Improved Salting Out ExtractionPreconcentration Method for the Determination of Nitroaromatics and Nitramines in Water

Paul H. Miyares and Thomas F. Jenkins

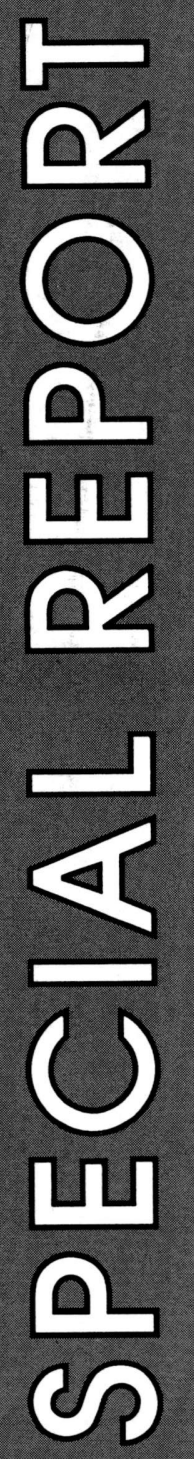


For conversion of SI metric units to U.S./British customary units

of measurement consult ASTM Standard E380, Metric Practice

Guide, published by the American Society for Testing and

Materials, 1916 Race St., Philadelphia, Pa. 19103.

This report is printed on paper that contains a minimum of $50 \%$ recycled material. 


\section{Special Report 91-18}

\section{Improved Salting Out Extraction- Preconcentration Method for the Determination of Nitroaromatics and Nitramines in Water}

Paul H. Miyares and Thomas F. Jenkins 


\section{PREFACE}

This report was prepared by Paul H. Miyares and Dr. Thomas F. Jenkins, Research Chemists, Geochemical Sciences Branch, Research Division, U.S. Army Cold Regions Research and Engineering Laboratory. Funding for this research was provided by the U.S. Army Toxic and Hazardous Materials Agency, Aberdeen Proving Ground, Maryland, Martin H. Stutz, Project Monitor, and the Waterways Experiment Station, Vicksburg, Mississippi, Ann Strong, Project Monitor (AF25).

The authors gratefully acknowledge Marianne E. Walsh and Daniel C. Leggett, CRREL, for their technical reviews of this manuscript. The authors also acknowledge Dr. C.L. Grant, Professor Emeritus, University of New Hampshire, for his technical contributions to this manuscript. Dr. Joseph Solsky, U.S. Army Engineer Division, Missouri River, Ann Strong, Waterways Experiment Station, and Marianne E. Walsh, CRREL, are acknowledged for supplying groundwater samples used for method evaluations, and Dr. David Kaplan, U.S. Army Natick Laboratories, for supplying standards for 2-Am-DNT and 4-Am-DNT.

This publication reflects the personal views of the authors and does not suggest or reflect the policy, practices, programs, or doctrine of the U.S. Army or Government of the United States. The contents of this report are not to be used for advertising or promotional purposes. Citation of brand names does not constitute an official endorsement or approval of the use of such commercial products. 


\section{CONTENTS}

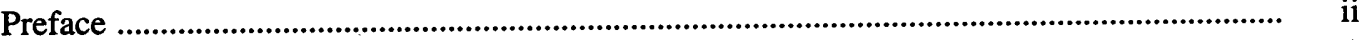

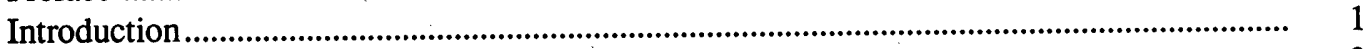

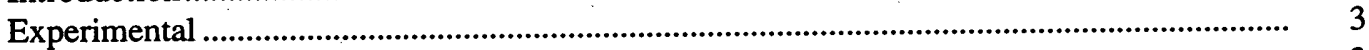

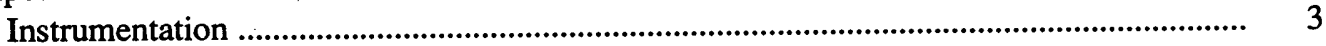

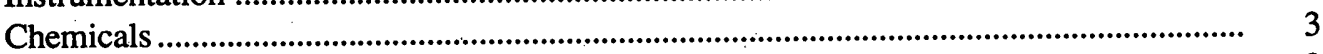

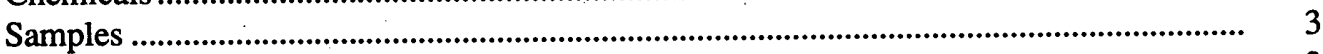

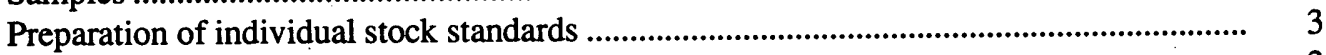

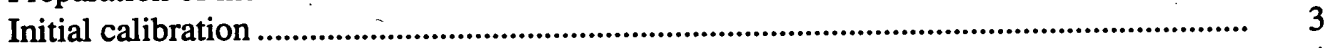

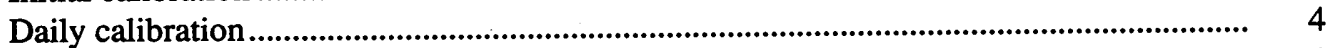

Preparation of solutions for certified reporting limit test .............................................. 4

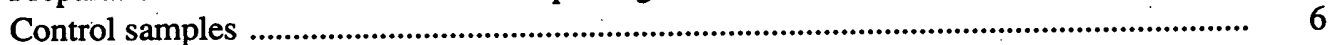

Sample extraction and analysis ............................................................................... 7

Direct injection method .............................................................................................. 7

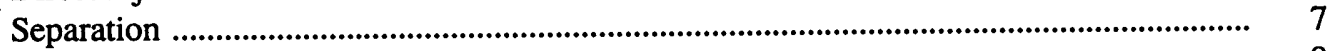

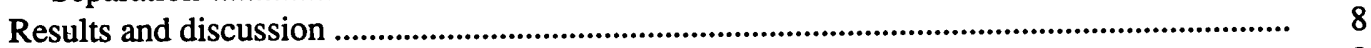

Optimization of salting-out extraction procedures ........................................................ 8

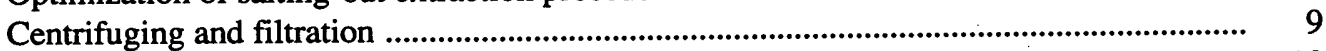

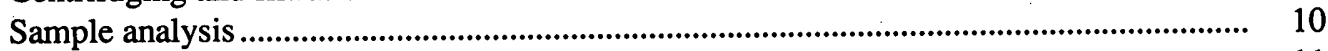

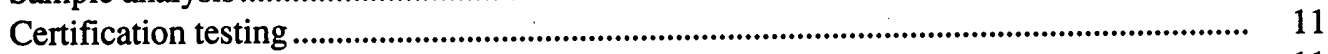

Low-concentration direct injecting ........................................................................... 11

Analysis of field samples ......................................................................................... 12

Confirmation separation ............................................................................................ 12

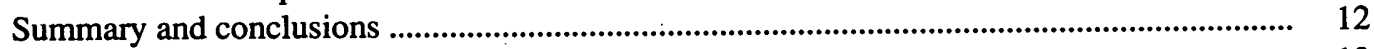

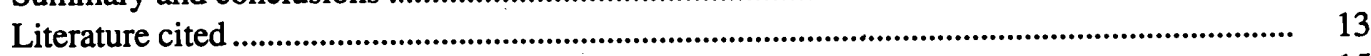

Appendix A: Derivation of equation 1 .............................................................................. 15

Appendix B: Method documentation in USATHAMA format (improved salting-out solvent extraction method)

Appendix C: Method documentation in USATHAMA format (low-level, direct injection method)

Abstract

\section{ILLUSTRATIONS}

Figure

1. Flow diagram for preparation of daily calibration stock solution and combined analyte spiking solution

2. Improved salting-out extraction protocol ........................................................................

3. Primary separation for the improved salting-out procedure .......................................... 7

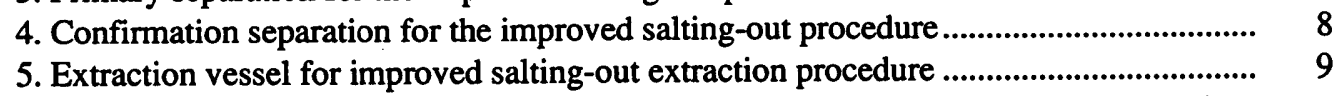

6. Ultraviolet spectra for 2,6-DNT from 180 to $300 \mathrm{~nm}$ in an $\mathrm{H}_{2} \mathrm{O}-\mathrm{MeOH}-\mathrm{THF}$ matrix obtained by stopped-flow HPLC-UV, 1100- $\mu \mathrm{L}$ injection ................................... 11

7. Direct comparison of method capabilities based on separation and detection ................ 12 


\section{TABLES}

Table

1. Recommended water quality criteria and measurement capability for

HMX, RDX, TNT, 2,4-DNT and 2,6-DNT ......................................................... 1

2. Certified reporting limits for original salting-out extraction technique ............................. 2

3. Dilutions for precertification calibration standards ........................................................... 4

4. Concentrations of the analytes in the combined and initial calibration standards ............. 4

5. Concentrations of combined daily analyte calibration stock and daily calibration standard ......................................................................................... 4

6. Dilution outline of certification spiking solutions ............................................................. 5

7. Concentrations of certification combined stock and spiking solutions .............................. 5

8. Concentration of analytes in certification samples ............................................................... 6

9. Retention times and capacity factors ................................................................................ 8

10. Partition coefficients for various organic solutes between acetonitrile and salt water at $23.5 \pm 1{ }^{\circ} \mathrm{C}$

11. Mean absorbance for analytes of interest at $\lambda=254$ vs injection loop size

12. Chromatographic resolution of analytes for separation on an LC-8 column vs

injection loop size ..................................................................................... 10

13. Certified reporting limits for improved salting-out extraction method ............................. 11

14. Certified reporting limits for low-concentration direct injection/solute focusing ............ 11 


\title{
Improved Salting Out Extraction-Preconcentration Method for the Determination of Nitroaromatics and Nitramines in Water
}

\author{
PAUL H. MIYARES AND THOMAS F. JENKINS
}

\section{INTRODUCTION}

During the early 1980s, CRREL developed a Reversed-Phase High Performance Liquid Chromatographic (RP-HPLC) method for the determination of the following explosives in wastewater from Army Ammunition Plants: octahydro-1,3,5,7-tetranitro-1,3,5,7-tetrazocine (HMX), hexahydro-1,3,5-trinitro-1,3,5-triazine (RDX), 2,4,6-trinitrotoluene (TNT) and 2,4-dinitrotoluene (2,4DNT) (Jenkins et al. 1984, Bauer et al. 1986, Jenkins et al. 1986). Later, a protocol was developed for the determination of munitions residues in soil that included an RP-HPLC separation that provided for simultaneous determination of HMX, RDX, TNT and 2,4-DNT plus 1,3,5-trinitrobenzene(TNB), 1,3-dinitrobenzene(DNB), methyl-2,4,6-trinitrophenylnitramine (tetryl) and the three isomers of nitrotoluene, meta (m-NT), para (p-NT) and ortho (o-NT) (Jenkins and Walsh 1987, Jenkins et al. 1988a, Bauer et al. 1989, Jenkins et al. 1989, USEPA
1990). This separation was subsequently found to be useful for water analysis as well (Jenkins et al. 1988b). In both RP-HPLC water methods, samples were diluted with a polar solvent to reduce adsorption on membranes during filtration (Walsh et al. 1988) and to matrix match the sample and eluent. Unfortunately, neither separation adequately resolves isomers of important manufacturing by-products-2,4-DNT and 2,6-DNT - and biodegradation product isomers-2-amino-4,6-dinitrotoluene (2Am-DNT) and 4-amino-2,6-dinitrotoluene (4-AmDNT).

In 1987, Oak Ridge National Laboratory (ORNL) published recommendations for the maximum concentrations of 2,4-DNT $(0.17 \mu \mathrm{g} / \mathrm{L})$ and $2,6-\mathrm{DNT}(6.8 \mathrm{ng} / \mathrm{L})$ for safe drinking water (Table 1) (Etnier 1987). In 198889, the U.S. Environmental Protection Agency's (USEPA) Office of Drinking Water published health advisories and water quality criteria for $\mathrm{HMX}, \mathrm{RDX}$, TNT, 2,4-DNT and 2,6-DNT (Table 1) for safe levels of

Table 1. Recommended water quality criteria and measurement capability for HMX, RDX, TNT, 2,4DNT and 2,6-DNT.

\begin{tabular}{lccccc} 
& \multicolumn{5}{c}{ Concentration $(\mu g / L)$} \\
\cline { 2 - 6 } & $H M X$ & $R D X$ & $T N T$ & $2,4-D N T$ & $2,6-D N T$ \\
\hline Water quality criteria* & & & & & \\
U.S. Navy (BUMED 1980) & - & - & 50 & - & - \\
U.S. AMBRDL (NRC 1982) & 400 & 0.3 & 1.0 & 0.1 & 0.007 \\
U.S. EPA (Khanna et al. 1988-1989) & & & & 0.17 & 0.0068 \\
ORNL (Etnier 1987) & & & & & \\
Current measurement capability & & & & & \\
RP-HPLC & 13.0 & 14.0 & 6.9 & 5.7 & 9.4 \\
Direct injection method (Jenkins et al. 1988b) & - & 7.7 & 1.0 & - & - \\
Solid-phase extraction (Bicking and Summer 1986) & 5.1 & 7.5 & 1.3 & 0.79 & 2.7 \\
Solid-phase extraction (Valis et al. 1989) & & & & & \\
GC-ECD & - & $\dagger$ & 1.0 & - & - \\
Toluene extraction (Belkin et al. 1985) & & & & \\
Toluene extraction isoamyl acetate (Hable et al. 1991) & 6.0 & 0.3 & 0.06 & 0.04 & 0.003 \\
\hline
\end{tabular}

* Risk factor $1 \times 10^{6}$

$\dagger$ Not recommended for RDX (Belkin et al. 1985). 
munitions in drinking water (Khanna et al. 1988-89). At that time, there were very few reported analytical techniques that could detect $1.0 \mathrm{mg} / \mathrm{L}$ of TNT and none that could detect $0.3 \mu \mathrm{g} / \mathrm{L}$ of RDX (Table 1 ). Detection limits reported for the direct injection RP-HPLC method developed by Jenkins et al. (1988b) were not adequate to meet the proposed health advisories and water quality criteria for HMX, RDX, TNT or the two isomers of DNT. Those methods with reported detection limits below the USEPA criteria for TNT all involved some form of extraction and preconcentration (Belkin et al. 1985, Bicking and Summer 1986, Valis et al. 1989), either liquid-liquid extraction with a non-polar solvent or solid phase extraction.

Spanggord et al. (1982) described a conventional diethyl ether extraction of munitions wastewater, while Phillips et al. (1983) used methylene chloride $\left(\mathrm{MeCl}_{2}\right)$ for liquid-liquid extraction of nitroaromatic compounds from biosludge, and Belkin et al. (1985) extracted water samples with toluene. Each of these techniques was inadequate for RDX because of poor extraction efficiency. Further, several of these methods used environmentally undesirable solvents for extraction.

Miyares and Jenkins (1990) developed a water method for nitroaromatics and nitramines that used salting-out solvent extraction with acetonitrile and evaporative preconcentration followed by RP-HPLC separation on an LC-8 (3.3-cm $\times 4.6-\mathrm{mm}, 3-\mu \mathrm{m})$ column. This method requires 5-minutes of vigorous, manual shaking of a $500-\mathrm{mL}$ separatory funnel containing $400 \mathrm{~mL}$ of sample, $130 \mathrm{~g}$ of sodium chloride $(\mathrm{NaCl})$ and $100 \mathrm{~mL}$ of acetonitrile (ACN). The technique had the capability of determining simultaneously RDX, TNB, DNB, TNT, 2,4-DNT, 2,6-DNT, 2-Am-DNT and 4-Am-DNT at concentrations below the microgram-per-liter level, with recoveries in excess of $95 \%$ (Table 2). Although Certified Reporting Limits (CRL) were adequate to meet the USEPA health advisories and water criteria for TNT,

Table 2. Certified reporting limits (CRL) for original salting-out extraction technique (Miyares and Jenkins 1990).

\begin{tabular}{lcc} 
Analyte & $\begin{array}{c}C R L \\
(\mu g / L)\end{array}$ & $\begin{array}{c}\text { Recovery } \\
(\%)\end{array}$ \\
\hline RDX & 0.836 & 101 \\
TNB & 0.258 & 137 \\
DNB & 0.108 & 99.0 \\
TNT & 0.113 & 88.8 \\
2,4-DNT & 0.021 & 94.8 \\
2,6-DNT & 0.314 & 93.9 \\
2-Am-DNT & 0.035 & 102 \\
4-Am-DNT & 0.060 & 100 \\
\hline
\end{tabular}

RDX and 2,4-DNT, the current criteria for 2,6-DNT were not met.

Maskarinec et al. (1984), Richard and Junk (1986) and Valis et al. (1989) reported the use of Solid Phase Extraction (SPE) for preconcentration of munitions components from water. SPE yields considerable preconcentration and is suitable for both laboratory and field applications owing to its simplicity. However, low recoveries of very polar solutes were observed in some cases because of breakthrough (Maskarinec et al. 1984) or incomplete release from the sorbents (Richard and Junk 1986), or both.

During the course of the work reported here, Hable et al. (1991) published an article that described two liquidliquid extraction Gas Chromatographic-Electron Capture Detector (GC-ECD) methods for munitions. The two methods employ toluene and isoamyl acetate as extractants for determining nitroaromatics and nitramine respectively. Both methods have detection limits meeting the USEPA health advisories and water quality criteria for their respective class of compounds. Unfortunately, this combined procedure requires two extractions and two analyses for each sample.

The objectives of our study were two-fold. The first was to develop a convenient technique with sufficient solute preconcentration to enable simultaneous RP-HPLC determinations of HMX, RDX, TNB, DNB, TNT, 2,4DNT, 2,6-DNT, 2-Am-DNT and 4-Am-DNT in water at levels that comply with the USEPA health advisories and water quality criteria. These compounds were chosen because our experience has shown them to be the more commonly detected munitions and munitions byproducts found in water samples from munitions waste sites. The salting-out solvent extraction (Miyares and Jenkins 1990) and the solid phase extraction techniques (Maskarinec et al. 1984, Bicking and Summer 1986, Richard and Junk 1986, Valis et al. 1989) were considered. Initial testing of solid phase extraction indicated that a $10-\mathrm{mL} / \mathrm{min}$ flow rate was the limiting value without reduction in analyte recovery. Also, the total volume of a sample was limited by the possibility of breakthrough for very polar solutes as well as the length of extraction time. A further observation indicated a possible variation in the tubes from batch to batch, increasing the solvent volume requirement for pretreatment. Therefore, we have chosen to concentrate our efforts on salting-out. The salting-out technique required further testing and improvement in concentration factors to reach desired levels for several of the analytes of interest, particularly for the two DNT isomers. A further goal was to achieve analyte preconcentration without the use of environmentally undesirable solvents (i.e., aromatic and chlorinated hydrocarbons). 
The second objective was to develop a direct-injection RP-HPLC method with enhanced detection capability. We used a technique known as solute focusing (Johnson and Dorsey 1990) in our efforts to improve the detection capabilities. Solute focusing involves trapping solutes in a narrow band at the head of the analytical column by injecting a large volume of sample in a weak solvent followed by elution with a stronger solvent. Johnson and Dorsey (1990) analyzed a single solution over a range of injection volumes and found that a linear relationship existed between injection volumes and detector response. We intended to increase our sample injection to the greatest volume possible without significantly reducing resolution.

\section{EXPERIMENTAL}

\section{Instrumentation}

All RP-HPLC determinations were made on a modular system composed of the following components:

1. A Spectra Physics Model SP8810 precision isocratic pump.

2. A Spectra Physics Model SP8490 variable wavelength UV detector set at $254 \mathrm{~nm}$ with a cell path length of $1 \mathrm{~cm}$.

3. A Hewlett Packard Model HP3393A digital integrator equipped with a Hewlett Packard Model HP9114B disk drive.

4. A Linear Model 500 strip chart recorder.

Samples were introduced by flushing an $1100-\mu \mathrm{L}$ sampling loop with $2.5 \mathrm{~mL}$ of sample and manually injecting the sample using a Rheodyne 7125 injector. The analytes were separated on a $7.5-\mathrm{cm} \times 4.6-\mathrm{mm}$ Supelco LC-8 $(3-\mu \mathrm{m})$ reversed-phase column eluted with a ternary eluent composed of water, methanol $(\mathrm{MeOH})$ and tetrahyrofuran (THF) $(70.7: 27.8: 1.5[\mathrm{v} / \mathrm{v} /$ v]) at a flow rate of $2.0 \mathrm{~mL} / \mathrm{min}$. The digital integrator was programmed to measure peak heights, which demonstrated better reproducibility than peak area measurements for low concentration samples.

\section{Chemicals}

Analytical standards for HMX, RDX, TNB, DNB, TNT, 2,4-DNT and 2,6-DNT were prepared from Standard Analytical Reference Materials (SARM) obtained from the U.S. Army Toxic and Hazardous Materials Agency (USATHAMA), Aberdeen Proving Ground, Maryland. Standards for 2-Am-DNT and 4-Am-DNT were obtained from Dr. David Kaplan, U.S. Army Natick Laboratories (Natick, Massachusetts) and their identity was confirmed by GC/MS analysis (Appendix B, Table B15). Standards were dried to constant weight in a vacuum desiccator over dry calcium chloride in the dark.

Methanol used in preparation of the eluent was Baker HPLC grade, acetonitrile (ACN) used to extract samples and prepare standards was Mallinckrodt ChromAR HPLC grade and THF for the eluent was either Baker HPLC or Aldrich HPLC grade. The $\mathrm{NaCl}$ used in the salting-out extraction was Baker reagent grade crystals. Water for preparation of eluent and spiked sample solutions was purified using a Milli-Q Type 1 Reagent Grade Water System (Millipore Corp). The mobile phase was prepared by combining appropriate portions of each component and vacuum filtering through a nylon membrane $(0.2 \mu \mathrm{m})$ to remove particulate matter and to degas.

\section{Samples}

Groundwater samples from Tidewater Community College, Suffolk, Virginia, and from the Nebraska Ordnance Plant, Mead, Nebraska, were provided by the U.S. Army Engineer Division, Missouri River, Omaha, Nebraska. Samples from the Crane-Rockeye Site, Crane, Indiana, were provided by the U.S. Army Waterways Experiment Station, Vicksburg, Mississippi, and samples from Eagle River Flats, Alaska, were provided by Marianne Walsh (CRREL).

\section{Preparation of individual}

stock standards

We prepared individual stock standards of $\mathrm{HMX}$, RDX, TNB, DNB, TNT, 2,4-DNT, 2,6-DNT, 2-AmDNT and 4-Am-DNT by weighing out approximately $250 \mathrm{mg}$ of each dried standard material to the nearest $0.01 \mathrm{mg}$, transferring to individual $250-\mathrm{mL}$ volumetric flasks and diluting to volume with acetonitrile. Stoppered joints were wrapped with Parafilm to retard evaporation and solutions were stored at $4^{\circ} \mathrm{C}$ in the dark. Concentrations of the analytes in these stock solutions were approximately $1000 \mathrm{mg} / \mathrm{L}$.

\section{Initial calibration}

We prepared duplicate combined analyte calibration stock standards (USATHAMA 1990) by adding 1.00 $\mathrm{mL}$ each of the HMX, RDX, TNB, DNB, TNT, 2,4 DNT, 2,6-DNT, 2-Am-DNT and 4-Am-DNT individual analyte stock standards to each of two 100 -mL volumetric flasks and diluting to volume with water (standards $\mathrm{A}$ and AA). The concentration of each analyte is approximately $10 \mathrm{mg} / \mathrm{L}$. A series of aqueous calibration solutions (B through I) and (BB through II) were each prepared from standards $\mathrm{A}$ and $\mathrm{AA}$, respectively, as outlined in Table 3. Concentrations of analytes in the initial combined analyte calibration stocks and dilutions thereof are presented in Table 4. Duplicate aliquots of each calibration solution were analyzed in random order. 
Table 3. Dilutions for precertification calibration standards. All dilutions are in water.

\begin{tabular}{lccc} 
Standards & $\begin{array}{c}\text { Dilution pattern } \\
(\mathrm{mL})\end{array}$ & $\begin{array}{c}\text { Approximate } \\
(\mathrm{mL})\end{array}$ & $\begin{array}{c}\text { Apencentration* } \\
\text { of analytes } \\
(\mu \mathrm{g} / \mathrm{L})\end{array}$ \\
\hline B (BB) & 2.00 of A (AA) & 100 & 200 \\
C (CC) & 1.00 of A (AA) & 100 & 100 \\
D (DD) & 20.0 of B (BB) & 100 & 40.0 \\
E (EE) & 10.0 of B (BB) & 100 & 20.0 \\
F (FF) & 10.0 of C (CC) & 100 & 10.0 \\
G (GG) & 10.0 of D (DD) & 100 & 4.00 \\
H (HH) & 2.00 of C (CC) & 100 & 2.00 \\
l (II) & 1.00 of C (CC) & 100 & 1.00 \\
\hline
\end{tabular}

* See Table 4 for concentrations for each analyte.

+ Solutions A and AA are the combined analyte stock standard prepared as described in text. the residual mean squares were calculated. We then compared the residuals of the two models for each analyte as described in USATHAMA (1990). The $F$ ratios at the $95 \%$ confidence level indicated that a linear model through the origin adequately described the data for all analytes. Thus, for daily calibration, a replicate single point calibration is sufficient.

\section{Daily calibration}

We prepared a daily calibration stock solution (standard N) according to the three-step process shown in Figure 1 . The daily calibration solution was prepared by diluting $1.00 \mathrm{~mL}$ of standard $\mathrm{N}$ to $100.0 \mathrm{~mL}$ in a volumetric flask with water (standard P). Concentrations of analytes in standards $\mathrm{N}$ and $\mathrm{P}$ are presented in Table 5. Standard $\mathrm{N}$ was stored in a refrigerator at $4^{\circ} \mathrm{C}$ for up to

Table 4. Concentrations of the analytes in the combined and initial calibration standards $(\mu \mathrm{g} / \mathrm{L})$.

\begin{tabular}{lcccccccccccc} 
Label & $H M X$ & $T N B$ & $R D X$ & $D N B$ & $N B$ & $T N T$ & $2,4-D N T$ & $2,6-D N T$ & $p-N T$ & $2-A m-D N T$ & $4-A m-D N T$ \\
\hline A(AA) & 10,010 & 10,010 & 10,000 & 10,010 & 10,600 & 10,000 & 10,030 & 10,050 & 9,970 & 10,000 & 11,600 \\
B(BB) & 200 & 200 & 200 & 200 & 211 & 200 & 201 & 201 & 199 & 200 & 232 \\
C(CC) & 100 & 100 & 100 & 100 & 106 & 100 & 100 & 100 & 100 & 100 & 116 \\
D(DD) & 40.0 & 40.0 & 40.0 & 40.0 & 42.3 & 40.0 & 40.1 & 40.2 & 39.9 & 40.0 & 46.3 \\
E(EE) & 20.0 & 20.0 & 20.0 & 20.0 & 21.1 & 20.0 & 20.1 & 20.1 & 19.9 & 20.0 & 23.2 \\
F(FF) & 10.0 & 10.0 & 10.0 & 10.0 & 10.6 & 10.0 & 10.0 & 10.0 & 10.0 & 10.0 & 11.6 \\
G(GG) & 4.00 & 4.00 & 4.00 & 4.00 & 4.23 & 4.00 & 4.01 & 4.02 & 3.99 & 4.00 & 4.63 \\
H(HH) & 2.00 & 2.00 & 2.00 & 2.00 & 2.11 & 2.00 & 2.01 & 2.01 & 1.99 & 2.00 & 2.32 \\
I(II) & 1.00 & 1.00 & 1.00 & 1.00 & 1.06 & 1.00 & 1.00 & 1.00 & 1.00 & 1.00 & 1.16 \\
\hline
\end{tabular}

Table 5. Concentrations of combined daily analyte calibration stock $(\mathrm{N})$ and daily calibration standard (P).

\begin{tabular}{lccc} 
Analyte & $\begin{array}{c}\text { Individual } \\
\text { stock standards } \\
(\mathrm{mg} / \mathrm{L})\end{array}$ & $\begin{array}{c}N \\
(\mu \mathrm{g} / \mathrm{L})\end{array}$ & $\begin{array}{c}P \\
(\mu \mathrm{g} / L)\end{array}$ \\
\hline HMX & 1000 & 10000 & 100 \\
RDX & 1000 & 10000 & 100 \\
TNB & 1000 & 5000 & 50.0 \\
DNB & 1000 & 5000 & 50.0 \\
TNT & 1000 & 1000 & 10.0 \\
2,4-DNT & 1000 & 500 & 5.00 \\
2,6-DNT & 1010 & 502 & 5.02 \\
2-Am-DNT & 702 & 1400 & 14.0 \\
4-Am-DNT & 579 & 1160 & 11.6 \\
\hline
\end{tabular}

A linear model with intercept was fitted to the data for each analyte. The lack of fit and error mean squares were tested for significance at the $95 \%$ confidence level as described in USATHAMA (1990). The $F$-ratios for standards over the entire concentration range indicated that a linear model adequately described the data. A zero intercept linear model was then fitted to each data set and
28 days but standard $\mathrm{P}$ was prepared daily. Standard $\mathrm{P}$ was analyzed in triplicate at the beginning of each day of analysis, and singly at the middle and at the end of each day of analysis.

Response factors for each analyte were obtained from the mean peak height and compared with the response factors obtained for the initial calibration. According to USATHAMA (1990), mean response factors for daily calibration must agree within $\pm 25 \%$ of the initial response factors for the first seven daily calibrations. Subsequent daily response factors must agree with the initial factors within two standard deviations (based on the first seven daily calibrations). If these criteria are not met, a new initial calibration must be obtained.

\section{Preparation of solutions for certified reporting limit test}

A combined analyte spiking stock solution (standard Q) was prepared in the same manner as standard N (Fig. 1). Spiking solutions (standards $R$ through $V$ ) were prepared as outlined in Table 6. Concentrations of aralytes in standards $\mathrm{Q}$ through $\mathrm{V}$ are presented in Table 7. CRL solutions were prepared by diluting $1.00-\mathrm{mL}$ aliquots of 


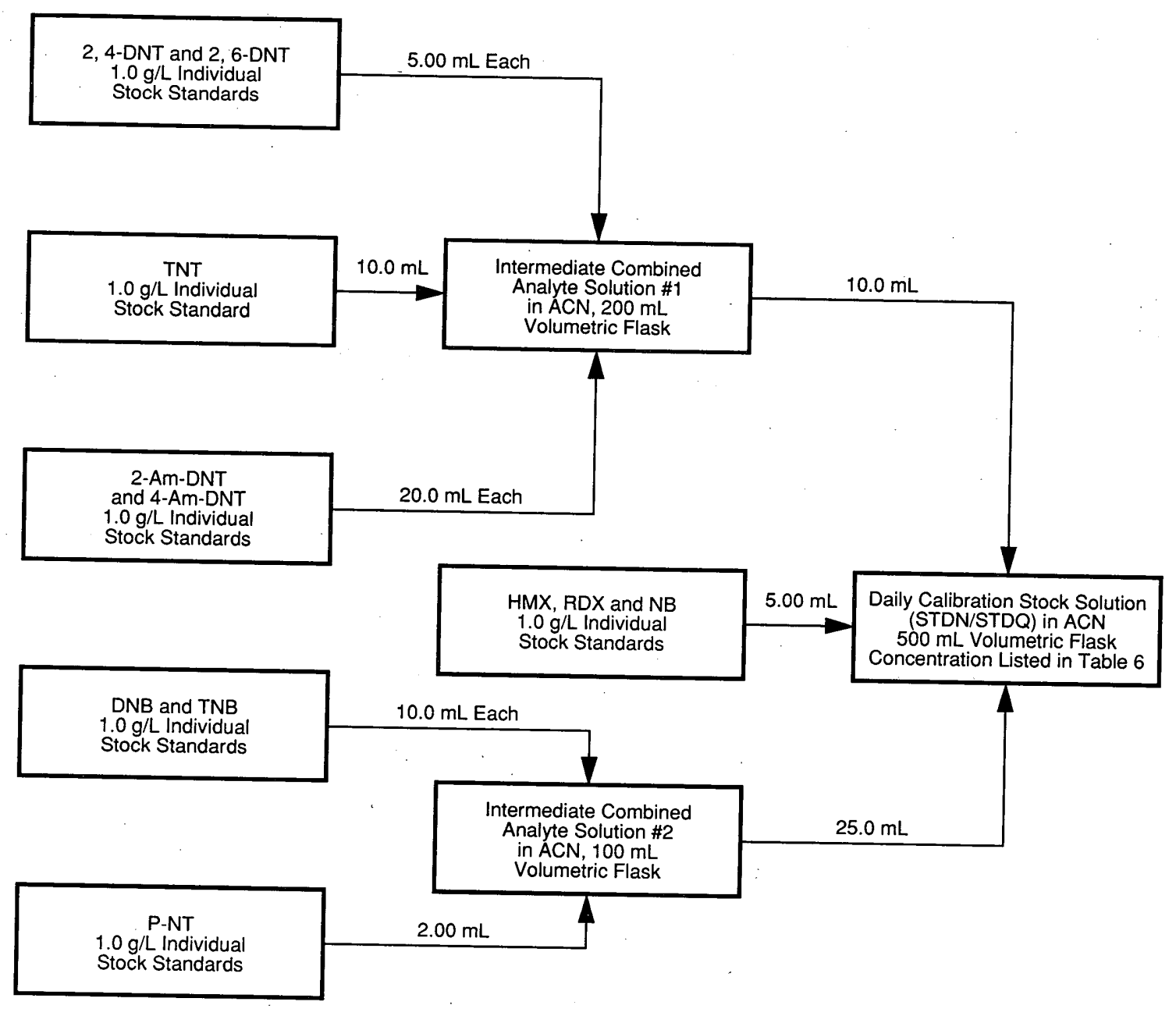

Figure 1. Flow diagram for preparation of daily calibration stock solution (standard $N$ ) and combined analyte spiking solution (standard $Q$ ).

Table 6. Dilution outline of certification spiking solutions.* All dilutions are in acetonitrile.

\begin{tabular}{cccc} 
Solution & Level & $\begin{array}{c}\text { Volume of } Q \\
(\mathrm{~mL})\end{array}$ & $\begin{array}{c}\text { Volume of flask } \\
(\mathrm{mL})\end{array}$ \\
\hline $\mathrm{R}$ & $10 x^{\dagger}$ & 20.0 & 100 \\
$\mathrm{~S}$ & $5 x$ & 10.0 & 100 \\
$\mathrm{~T}$ & $2 x$ & 4.00 & 100 \\
$\mathrm{U}$ & $1 x$ & 2.00 & 100 \\
$\mathrm{~V}$ & $0.5 x$ & 1.00 & 100 \\
\hline
\end{tabular}

* Concentration of analytes in the certification spiking solutions are listed in Table 7.

$\dagger x$ is the target concentration per USATHAMA (1990).
Table 7. Concentrations of certification combined stock and spiking solutions $(\mu \mathrm{g} / \mathbf{L})$.

\begin{tabular}{lrrrccc} 
Analytes & $Q^{*}$ & $R$ & $S$ & $T$ & $U$ & $V$ \\
\hline HMX & 10010 & 2000 & 1000 & 400 & 200 & 100 \\
TNB & 5000 & 1000 & 500 & 200 & 100 & 50 \\
RDX & 10000 & 2000 & 1000 & 400 & 200 & 100 \\
DNB & 5000 & 1000 & 500 & 200 & 100 & 50.0 \\
TNT & 1000 & 200 & 100 & 40.0 & 20.0 & 10.0 \\
2,4-DNT & 502 & 100 & 50.2 & 20.1 & 10.0 & 5.02 \\
2,6-DNT & 502 & 101 & 50.2 & 20.1 & 10.1 & 5.02 \\
2-Am-DNT & 1400 & 281 & 140 & 56.2 & 28.1 & 14.0 \\
2-Am-DNT & 1160 & 232 & 116 & 46.4 & 23.2 & 11.6 \\
\hline
\end{tabular}

* Solution $\mathrm{Q}$ is the certification combined stock solution. 
Table 8. Concentrations $(\mu \mathrm{g} / \mathrm{L})$ of analytes in certification samples.

\begin{tabular}{lccccl} 
Analytes & $0.5 \mathrm{x}^{*}$ & $1 \mathrm{x}$ & $2 \mathrm{x}$ & $5 \mathrm{x}$ & $10 \mathrm{x}$ \\
\hline HMX & 0.050 & 0.100 & 0.200 & 0.501 & 1.00 \\
TNB & 0.025 & 0.050 & 0.100 & 0.250 & 0.500 \\
RDX & 0.050 & 0.100 & 0.200 & 0.500 & 1.00 \\
DNB & 0.025 & 0.050 & 0.100 & 0.250 & 0.500 \\
TNT & 0.005 & 0.010 & 0.020 & 0.050 & 0.100 \\
2,4-DNT & 0.003 & 0.005 & 0.010 & 0.025 & 0.050 \\
2,6-DNT & 0.003 & 0.005 & 0.010 & 0.025 & 0.050 \\
2-Am-DNT & 0.007 & 0.014 & 0.028 & 0.070 & 0.140 \\
4-Am-DNT & 0.006 & 0.012 & 0.023 & 0.058 & 0.116 \\
\hline
\end{tabular}

$* x$ is the target concentration per USATHAMA (1990). appropriate spiking solutions to $2000 \mathrm{~mL}$ in volumetric flasks with Milli-Q water. The concentrations of analytes in the these solutions are presented in Table 8. They were extracted and analyzed as described below for water samples.

\section{Control samples}

Analytical control samples were prepared at 1.00 $\mu \mathrm{g} / \mathrm{L}$ for each of HMX, RDX, TNB, DNB, TNT, 2,4DNT, 2,6-DNT, 2-Am-DNT and 4-Am-DNT. Control samples were treated identically to groundwater samples as described above.

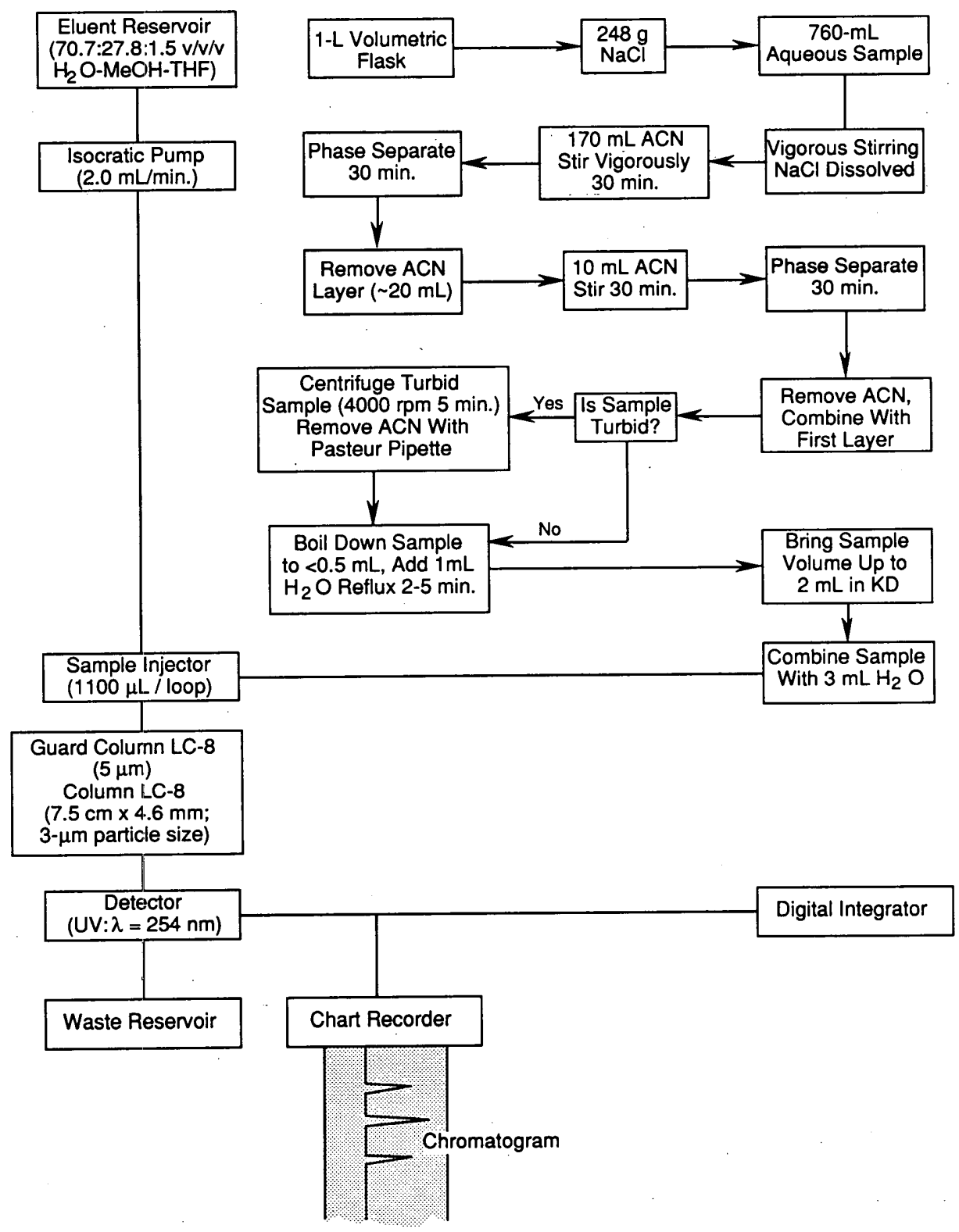

Figure 2. Improved salting-out extraction protocol. 
Sample extraction and analysis

\section{Salting-out extraction}

The day prior to analysis, we washed all glassware with soap and water, rinsed it with distilled water, rinsed it with acetone and finally rinsed it with Type 1 water (Millipore Corp.). The glassware was filled with Type 1 water and allowed to stand overnight. Immediately prior to use, our Kuderna-Danish concentrators were rinsed with ACN, and all other glassware was given a final rinse with Type 1 water.

A 760-mL aliquot of each water sample was measured by graduated cylinder and transferred into a $1000-\mathrm{mL}$ volumetric flask containing $248 \mathrm{~g}$ of $\mathrm{NaCl}$ and a magnetic bar. Each sample was stirred vigorously on a stirring plate until the $\mathrm{NaCl}$ was completely dissolved. Then $170 \mathrm{~mL}$ of $\mathrm{ACN}$ was pipetted into each flask and the speed of the stirring plate was adjusted such that all of the ACN was drawn down into the aqueous phase by vortex action. After 30 minutes, the stirrer was turned off and the samples allowed to stand for 30 minutes to allow phase separation. The ACN phase collects in the neck of the volumetric flask where about $23 \mathrm{~mL}$ was recovered with a Pasteur pipette and transferred to a $40-\mathrm{mL}$ glass vial with a Teflon faced cap. A fresh $10-\mathrm{mL}$ aliquot of $\mathrm{ACN}$ was then added to each volumetric flask for a second extraction. Samples were stirred for another 30 minutes, allowed to stand 30 minutes and the second ACN extracts were collected and combined with the first. Turbid extracts were centrifuged at $4000 \mathrm{rpm}$ for 5 minutes and the $\mathrm{ACN}$ was removed from the vials with a Pasteur pipette and transferred to clean $40-\mathrm{mL}$ vials.

\section{Extract preconcentration}

The collected extracts ( $33 \mathrm{~mL}$ per sample) were transferred to Kuderna-Danish (KD) microconcentrators and the volumes reduced to about $0.5 \mathrm{~mL}$. Then a $1.0-\mathrm{mL}$ aliquot of water was added to each. The samples were allowed to continue to reflux for 2-5 minutes to further reduce the $\mathrm{ACN}$ concentration. The volumes were then brought up to $2.0 \mathrm{~mL}$ with water, and the samples were removed from the Kuderna-Danish concentrator and combined with $3.00 \mathrm{~mL}$ of water in scintillation vials. Samples are not diluted with ACN because the solutefocusing technique requires that the sample must be a much weaker solvent than the mobile phase so that the solutes will be adsorbed at the head of the column. The entire salting-out protocol is outlined in Figure 2.

\section{Direct injection method}

A 10.0-mL aliquot of the water sample was transferred to a scintillation vial. A $100-\mu \mathrm{L}$ aliquot of $\mathrm{MeOH}$ was added and the sample shaken. The resulting solution was filtered through a Millex SR $0.5-\mu \mathrm{m}$ disposable filter,

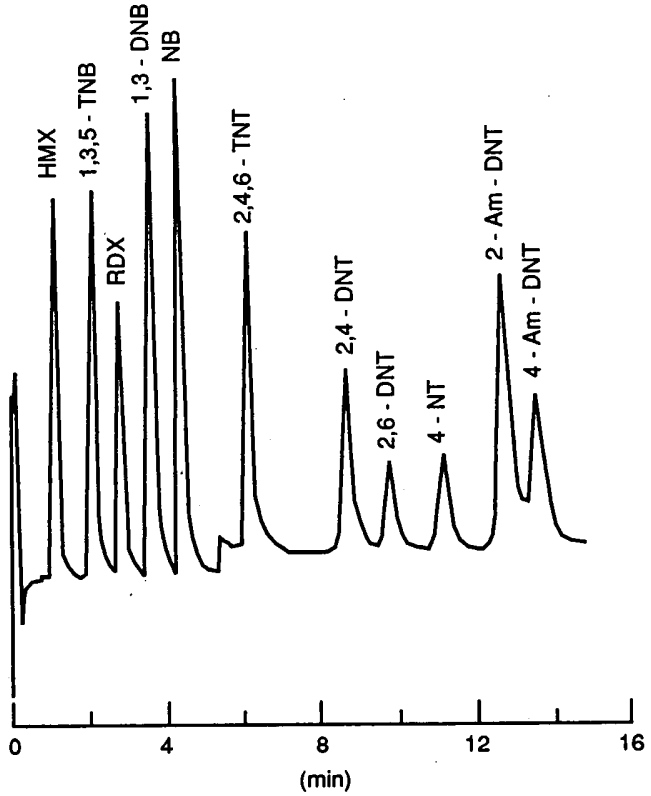

Figure 3. Primary separation for the improved salting-out procedure.

Column: $L C-8(7.5 \mathrm{~cm} \times 4.6 \mathrm{~mm}$, $3 \mu \mathrm{m})$

Eluent: $70.7: 27.8: 1.5(v / v / v)$ $\mathrm{H}_{2} \mathrm{O}-\mathrm{MeOH}-\mathrm{THF}$

Flow: $2.0 \mathrm{~mL} / \mathrm{min}$

Detector, $u v: \quad \lambda=254 \mathrm{~nm}$

Injection volume: $1100 \mu \mathrm{L}$.

the first $3 \mathrm{~mL}$ being discarded and the remainder being collected in a clean vial. Samples were analyzed using the same separation and mode of detection as used for the concentrated extracts.

\section{Separation}

The primary analytical separation was achieved on an LC-8 (7.5-cm $\times 4.6-\mathrm{mm}, 3-\mu \mathrm{m})$ column preceded by an LC-8 guard column $(5 \mu \mathrm{m})$, eluted with a ternary eluent composed of water-MeOH-THF (70.7:27.8:1.5 [v/v/ v]) at a flow rate of $2.0 \mathrm{~mL} / \mathrm{min}$. Retention times and capacity factors for the primary analytes of interest as well as potential interfering compounds are presented in Table 9. A chromatogram of the primary separation is shown in Figure 3. Suspected analytes were confirmed on a set of columns consisting of an LC-8 $(5-\mu \mathrm{m})$ guard column, followed by an LC-8 $(3.3-\mathrm{cm} \times 4.6-\mathrm{mm}, 3-\mu \mathrm{m})$ column, followed by an LC-CN $(3.3-\mathrm{cm} \times 4.6-\mathrm{mm}, 3-$ $\mu \mathrm{m})$ column connected in series. This series was eluted with the same eluent as the primary analytical column at a flow of $1.5 \mathrm{~mL} / \mathrm{min}$. Retention times and capacity factors of the primary analytes for the confirmatory separation are also presented in Table 9. A chromatogram of the confirmatory separation is shown in Figure 4. 
Table 9. Retention times and capacity factors.

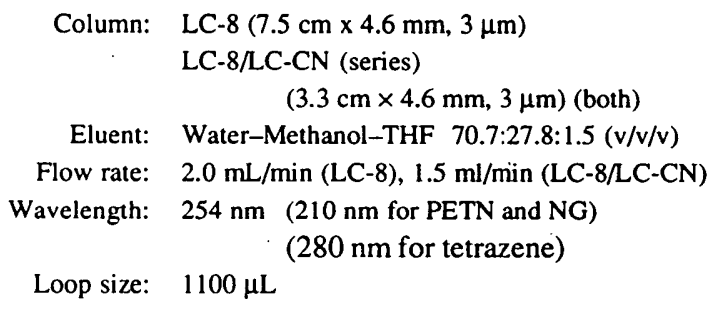

\begin{tabular}{|c|c|c|c|c|}
\hline \multirow[b]{2}{*}{ Analyte } & \multicolumn{2}{|c|}{ Retention time ( $\mathrm{min}$ ) } & \multicolumn{2}{|c|}{ Capacity factor* $\left(\mathbf{K}^{\prime}\right)$} \\
\hline & $L C \cdot 8 \quad L$ & $L C-8 / L C-C N$ & $\overline{L C-8}$ & $L C-8 / L C-C N$ \\
\hline $\mathrm{NO}_{3}^{-}$ & 0.55 & 0.615 & - & - \\
\hline Tetrazene & unretained & - & - & - \\
\hline Picric acid & unretained & - & - & - \\
\hline 2,4-DNPhenol & 1.18 & - & 1.15 & - \\
\hline SEX & 1.44 & - & 1.62 & - \\
\hline TAX & 1.75 & - & 2.18 & - \\
\hline HMX & 2.19 & 6.91 & 2.98 & 10.2 \\
\hline 2,6-DAm-NT & 2.21 & - & 3.02 & - \\
\hline TNB & 3.09 & 3.35 & 4.62 & 4.45 \\
\hline 3-Am-NB & 3.17 & - & 4.76 & - \\
\hline TNBA & 3.21 & - & 4.84 & - \\
\hline 1,4-DNB & 3.52 & - & 5.40 & - \\
\hline RDX & 3.60 & 4.97 & 5.55 & 7.09 \\
\hline 2,4-DAm-NT & 3.77 & - & 5.85 & - \\
\hline DNB & 4.32 & 4.12 & 6.85 & 5.69 \\
\hline NB & 4.85 & 4.34 & 7.82 & 6.06 \\
\hline 2-Am-4-NT & 5.30 & - & 8.64 & - \\
\hline 1,2-DNB & 5.59 & - & 9.16 & - \\
\hline Benzene & 5.83 & 4.55 & 9.60 & 6.40 \\
\hline 4-Am-2-NT & 6.06 & - & 10.0 & - \\
\hline TNT & 6.47 & 5.83 & 10.8 & 8.48 \\
\hline 3,5-DNA & 7.07 & - & 11.9 & - \\
\hline 2,4-DNT & 8.66 & 7.11 & 14.8 & 10.6 \\
\hline NG & 8.98 & - & 15.3 & - \\
\hline $2,4,5-\mathrm{TNT}$ & 9.10 & - & 15.6 & - \\
\hline Tetryl & 9.57 & - & 16.4 & - \\
\hline 2,6-DNT & 9.65 & 7.63 & 16.6 & 11.4 \\
\hline o-NT & 10.7 & 8.08 & 18.4 & 12.1 \\
\hline $\mathrm{p}-\mathrm{NT}$ & 10.8 & 8.18 & 18.6 & 12.3 \\
\hline $\mathrm{m}-\mathrm{NT}$ & 11.2 & 8.78 & 19.3 & 13.3 \\
\hline 2-Am-DNT & 12.2 & 9.75 & 21.2 & 14.9 \\
\hline 4-Am-DNT & 12.9 & 10.47 & 22.5 & 16.0 \\
\hline Toluene & 13.9 & 9.37 & 24.3 & 14.2 \\
\hline PETN & 22.4 & - & 39.8 & - \\
\hline 2,3,4-TNT & 30.0 & - & 53.6 & - \\
\hline
\end{tabular}

*Capacity factor is calculated on the unretained peak of nitrate $\left(\mathrm{NO}_{3}^{-}\right)$.

$$
\begin{aligned}
K^{\prime} & =\frac{\left(\bar{t}_{\mathrm{r}}-\bar{t}_{\mathrm{NO}_{3}}\right)}{\bar{t}_{\mathrm{NO}_{3}}} \\
\bar{t}_{\mathrm{r}} & =\text { mean retention time of the analyte }(\mathrm{min}) . \\
\bar{t}_{\mathrm{NO}_{3}} & =\text { mean retention time of unretained } \mathrm{NO}_{3}(\mathrm{~min}) .
\end{aligned}
$$

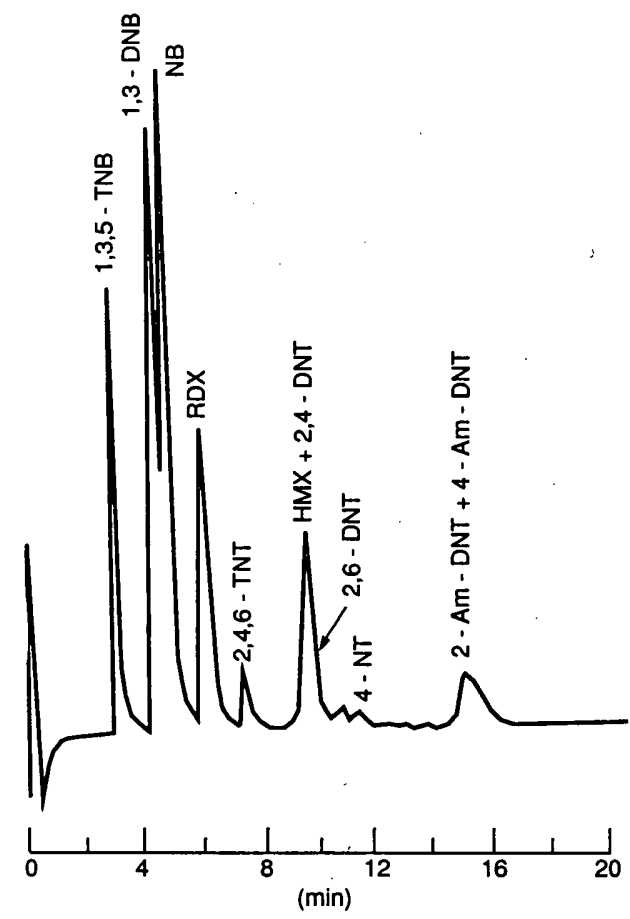

Figure 4. Confirmation separation for the improved salting-out procedure.

Column: LC-8/LC-CN series (both $3.3 \mathrm{~cm} \times 4.6 \mathrm{~mm}$,

$$
3 \mu \mathrm{m})
$$

Eluent: $\quad 70.7: 27.8: 1.5(v / v / v)$

$$
\mathrm{H}_{2} \mathrm{O}-\mathrm{MeOH}-\mathrm{THF}
$$

Flow: $1.5 \mathrm{~mL} / \mathrm{min}$

Detector, uv: $\lambda=254 \mathrm{~nm}$

Injection volume: $\quad 1100 \mu \mathrm{L}$.

\section{RESULTS AND DISCUSSION}

\section{Optimization of salting-out extraction procedures}

We enhanced the salting-out extraction method to make the most of the preconcentration factor, most significantly by increasing the initial volume of the sample, which would require a larger extraction vessel. We tried extracting an $800-\mathrm{mL}$ sample in a $1000-\mathrm{mL}$ separatory funnel, but this large vessel was far too cumbersome to shake manually.

We next considered using a $1-\mathrm{L}$ bottle with a magnetic stirrer to extract an $800-\mathrm{mL}$ sample. A preliminary experiment comparing the extraction efficiency for 5 minutes of manual shaking to 15 minutes of stirring showed no significant difference between the two. A drawback to stirring in bottles was the difficulty in recovering the $\mathrm{ACN}$ phase. As an alternative to bottles, 


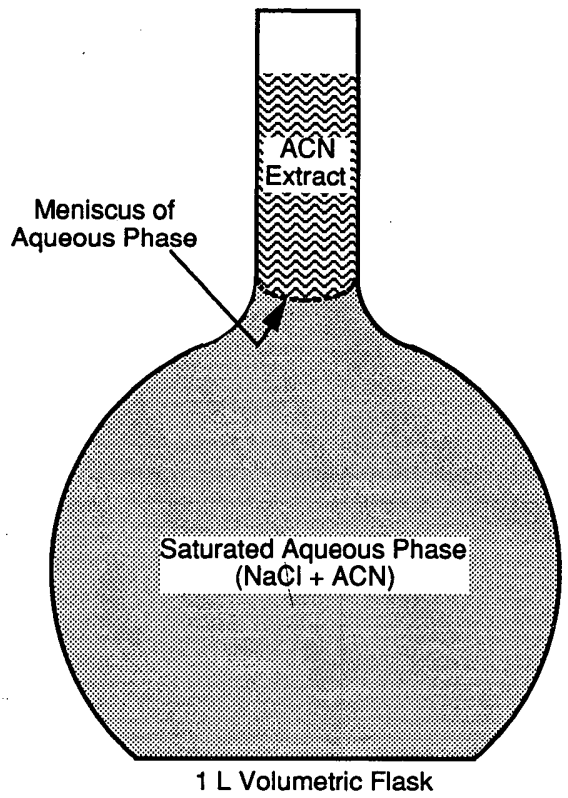

Figure 5. Extraction vessel for improved salting-out extraction procedure.

Belkin et al. (1985) suggested stirring the sample in a 1-L volumetric flask, which acted as an inverted separatory funnel for solvents with specific gravities lower than water (Fig. 5). This approach retained the advantage of reducing labor, allowed large samples $(800 \mathrm{~mL})$ to be extracted with easy recovery of extract and allowed for several samples to be processed simultaneously. We chose round volumetric flasks over square ones because of improved mixing.

We decided on the proper sample size for the 1-L flask by determining the volume increase for an aqueous sample saturated with both $\mathrm{NaCl}$ and $\mathrm{ACN}$. The sample should fill the flask just into the bottom of the neck (Fig. 5), which was approximately $990 \mathrm{~mL}$. Preliminary studies showed that the volume of water increased by a factor of 1.3 when saturated with both $\mathrm{NaCl}$ and $\mathrm{ACN}$, translating into a sample size of 760 to $765 \mathrm{~mL}$, nearly double sample volume used in the previous salting-out procedure (Miyares and Jenkins 1990).

We determined earlier (Miyares and Jenkins 1990) that the optimum quantities of $\mathrm{NaCl}$ and $\mathrm{ACN}$ required for saturation were $32.5 \mathrm{~g}$ and $19.3 \mathrm{~mL}$ per $100 \mathrm{~mL}$ of water respectively. A 760-mL water sample would require $248 \mathrm{~g}$ and $147 \mathrm{~mL}$ of $\mathrm{NaCl}$ and $\mathrm{ACN}$ respectively. A remaining question concerned the additional volume of ACN required for acceptable extraction efficiency. Given the partition coefficient $\left(k_{\mathrm{p}}\right)$ and using eq $1,{ }^{*}$ we were able to estimate the volumes of aqueous $\left(V_{\mathrm{a}}\right)$ and

* See Appendix A for derivation. solvent $\left(V_{\mathrm{s}}\right)$ phases required to achieve various extraction efficiencies (\% Extr).

$$
\% \operatorname{Extr}=\frac{100 V_{\mathrm{s}} k_{\mathrm{p}}}{V_{\mathrm{s}} k_{\mathrm{p}}+V_{\mathrm{a}}} .
$$

To achieve $95 \%$ recovery in a single extraction, we calculated that $7.3 \mathrm{~mL}$ of extract would be required for TNT and $48 \mathrm{~mL}$ for RDX based on $k_{\mathrm{p}}$ values of 2580 and 396 respectively. An extraction volume of $48 \mathrm{~mL}$ was impractical because of the total volume of the volumetric flask, so a compromise extract volume of $23 \mathrm{~mL}$ of ACN was chosen, requiring a total initial volume of $170 \mathrm{~mL}$ of ACN. This provided an estimated $90 \%$ recovery for RDX and greater percent recoveries for all other analytes. To increase recoveries, we added a second extraction using $10 \mathrm{~mL}$ of $\mathrm{ACN}$, resulting in a combined extraction volume of $33 \mathrm{~mL}$ and estimated recoveries greater than 98\% for all analytes. Table 10 lists partition coefficients for various organic solutes between $\mathrm{ACN}$ and salt water.

\section{Centrifuging and filtration}

Often times, water samples contain particulate matter that is not removed prior to extraction, and that will partition between the two phases. Recovered extracts are centrifuged for 5 minutes at $4000 \mathrm{rpm}$ so that the clear $\mathrm{ACN}$ can be drawn off and transferred to clean vials. The

Table 10. Partition coefficients for various organic solutes between acetonitrile and salt water $(325 \mathrm{~g}$ $\mathrm{NaCl} / \mathrm{L}$ ) at $23.5 \pm 1^{\circ} \mathrm{C}$ (from Jenkins and Miyares 1991).

\begin{tabular}{lcc}
\multicolumn{1}{c}{ Solute } & $\begin{array}{c}\mathrm{k}_{p} \text { octanoll } \\
\text { water }\end{array}$ & $\begin{array}{c}\mathrm{k}_{p} \text { acetonitrile/ } \\
\text { salt } \text { water* }\end{array}$ \\
\hline HMX & 1.1 & $633 \pm 48$ \\
Ethyl acetate & 5.0 & $620 \pm 30$ \\
RDX & 7.6 & $396 \pm 48$ \\
1,3,5-trinitrobenzene & 15.1 & $804 \pm 100$ \\
Dimethylphthalate & 29.5 & $542 \pm 71$ \\
1,3-dinitrobenzene & 30.9 & $445 \pm 22$ \\
cis-1,2-dichloroethylene & 42.7 & $232 \pm 11$ \\
Nitrobenzene & 70.8 & $415 \pm 51$ \\
2,4,6-trinitrotoluene & 72.0 & $2580 \pm 200$ \\
trans-1,2-dichloroethylene & 85.1 & $296 \pm 23$ \\
Chloroform & 93.3 & $450 \pm 21$ \\
2,4-dinitrotoluene & 95.5 & $987 \pm 38$ \\
2,6-dinitrotoluene & 104 & $1520 \pm 97$ \\
Benzene & 135 & $436 \pm 62$ \\
Diethylphthalate & 174 & $2360 \pm 260$ \\
Trichloroethylene & 195 & $606 \pm 21$ \\
m-Nitrotoluene & 282 & $1040 \pm 110$ \\
Chlorobenzene & 288 & $1235 \pm 84$ \\
Toluene & 490 & $1080 \pm 125$ \\
1,4-dichlorobenzene & 2400 & $2230 \pm 360$ \\
1,3-dichlorobenzene & 2400 & $2490 \pm 330$ \\
\hline * Mean of four or five determinations \pm standard deviation.
\end{tabular}

* Mean of four or five determinations \pm standard deviation. 
Table 11. Mean absorbance* $\left(\times 10^{3}\right)$ for analytes of interest at $\lambda=254$ vs injection loop size. Sample concentration, $20 \mu \mathrm{g} / \mathrm{L}$ per analyte.

\begin{tabular}{rrrrrrrrc} 
Loop size & $T N B$ & $R D X$ & $D N B$ & $T N T$ & $2,4-D N T$ & $2,6-D N T$ & 2-Am-DNT & 4-Am-DNT \\
\hline $100 \mu \mathrm{L}$ & 1.33 & 0.67 & 1.54 & 0.68 & 0.64 & 0.42 & 0.20 & 0.16 \\
$200 \mu \mathrm{L}$ & 2.35 & 1.15 & 2.71 & 1.22 & 1.14 & 0.76 & 0.37 & 0.29 \\
$500 \mu \mathrm{L}$ & 5.36 & 2.27 & 6.12 & 2.91 & 2.67 & 1.75 & 0.87 & 0.67 \\
$1100 \mu \mathrm{L}$ & 9.84 & 2.93 & 11.91 & 6.38 & 5.92 & 3.85 & 1.86 & 1.47 \\
\hline
\end{tabular}

* Mean of five replicates.

extracts often are cloudy after preconcentration, apparently because of small particles of $\mathrm{NaCl}$. These samples are clarified by filtering through Millex SR $0.5-\mu \mathrm{m}$ disposable filter membranes (Jenkins and Walsh 1987).

\section{Sample analysis}

\section{Separation for primary analysis}

We chose to employ an LC-8 separation that was similar to one developed by us earlier (Miyares and Jenkins 1990). However, improved resolution was obtained by using a longer column $(7.6 \mathrm{~cm}$ instead of 3.3 $\mathrm{cm}$ ); this increased the analysis time by only 7 minutes. One note is that the increase in analysis time is also partially caused by the increased sample loop size. The longer column provided sufficient resolution enabling quantitation of HMX, RDX, TNB, DNB, TNT, 2,4 DNT, 2,6-DNT, 2-Am-DNT and 4-Am-DNT (Fig. 3, Table 9).

\section{Sample loop size}

We studied the effect of increasing the size of the sample injected onto the column on detection capability, absorbance and resolution. Five replicate injections of an aqueous combined analyte solution $(20 \mathrm{mg} / \mathrm{L}$ per analyte) were each made for 100-, 200-, 500- and 1100$\mu \mathrm{L}$ sample loops. The absorbances of TNT, 2,4-DNT, 2,6-DNT, 2-Am-DNT and 4-Am-DNT were shown to be linear up to $1100 \mathrm{~mL}$ (Table 11). The absorbances of TNB, RDX and DNB were shown to be linear up to 500 $\mu \mathrm{L}$. We also observed a broadening of the bandwidth for TNB, RDX and DNB, which will reduce the peak height. These three analytes are more polar than the other five tested and are less apt to be well focused at the head of the column, thus causing the band broadening. We further found that the resolution was not significantly affected by the increase in loop size (Table 12), except between RDX and TNB, but the resolution for these two remained adequate in this case for quantitation. However, we discovered that the percentage of organic solvent in the injected sample had an effect on resolution: the organic solvent content should be maintained below $5 \%$ by volume to retain adequate resolution and peak shape. We also tested 5.0- and 10-mL sample loops, but found that the excessive pressure fluctuation upon injection interrupted the flow causing the pump to stop. We found that upon restarting the pump, it was difficult to maintain a steady and clean baseline, stopping us from determining the peak. In addition, we discovered that large pressure fluctuations are detrimental to HPLC columns by causing disruptions of the packing and channeling at the head of the column. Since many HPLC pumps have high- and low-pressure cutoffs, this problem can cause the pump to stop, interrupting the flow and the analysis. We found that using an $1100-\mu \mathrm{L}$ injection loop significantly increased our detection capability

Table 12. Chromatographic resolution of analytes for separation on an LC-8 $(7.5 \mathrm{~cm})$ column vs injection loop size. Sample concentration, $20 \mu \mathrm{g} / \mathrm{L}$ per analyte (Snyder et al. 1988).

\begin{tabular}{cccccccc} 
& \multicolumn{7}{c}{ Mean resolution* } \\
\cline { 2 - 8 } Loop size & TNB/RDX & RDX/DNB & DNB/TNT & TNT/2,4-DNT & 2,4-DNT/2,6-DNT & 2,6-DNT/2-Am-DNT & 2-Am-DNT/4-Am-DNT \\
\hline $100 \mu \mathrm{L}$ & 1.99 & 2.28 & 5.42 & 4.69 & 1.72 & 3.70 & 0.91 \\
$200 \mu \mathrm{L}$ & 1.98 & 2.36 & 5.10 & 4.51 & 1.69 & 3.54 & 0.95 \\
$500 \mu \mathrm{L}$ & 1.91 & 2.07 & 5.56 & 4.51 & 1.78 & 3.58 & 0.97 \\
$1100 \mu \mathrm{L}$ & 1.22 & 1.92 & 5.12 & 4.65 & 1.69 & 3.47 & 0.93 \\
\hline
\end{tabular}

* Mean of five replicates.

$$
\begin{aligned}
R_{\mathrm{S}} & =\text { resolution between two peaks }=1.18 \times\left(t_{2}-t_{1}\right) /\left(w_{2}+w_{1}\right) \\
t & =\text { retention time }(\mathrm{min}) \\
w & =\text { reak width at half height }(\mathrm{min})
\end{aligned}
$$

Baseline resolution, $R_{\mathrm{s}} \geq 1.50$. 


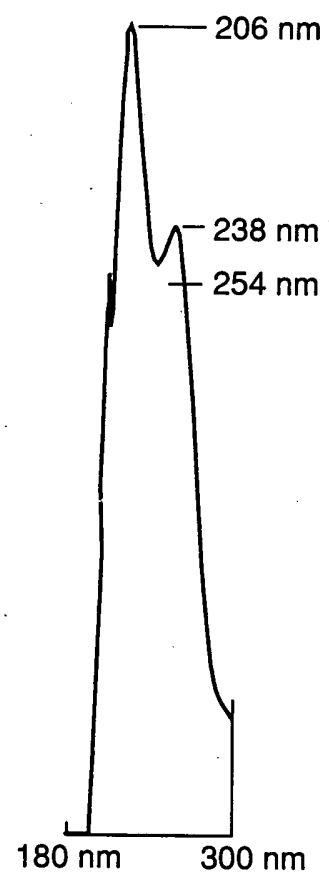

Figure 6. Ultraviolet spectra for 2,6-DNT from 180 to $300 \mathrm{~nm}$ in an $\mathrm{H}_{2} \mathrm{O}-\mathrm{MeOH}-\mathrm{THF}$ matrix obtained by stopped-flow HPLC$U V, 1100-\mu L$ injection.

Table 13. Certified reporting limits (CRL) for improved salting-out extraction method.

\begin{tabular}{lcc} 
Analyte & $\begin{array}{c}\text { CRL } \\
(\mu g / L)\end{array}$ & $\begin{array}{c}\text { Recovery } \\
(\%)\end{array}$ \\
\hline HMX & 0.271 & 118 \\
RDX & 0.260 & 101 \\
TNB & 0.129 & 63.0 \\
DNB & 0.090 & 78.9 \\
TNT & 0.011 & 74.1 \\
2,4-DNT & 0.007 & 78.0 \\
2,6-DNT & 0.006 & 79.5 \\
2-Am-DNT & 0.056 & 69.8 \\
4-Am-DNT & 0.054 & 84.0 \\
\hline
\end{tabular}

Table 14. Certified reporting limits (CRL) for low-concentration direct injection/solute focusing.

\begin{tabular}{lcc} 
Analyte & $\begin{array}{c}C R L \\
(\mu g / L)\end{array}$ & $\begin{array}{c}\text { Recovery } \\
(\%)\end{array}$ \\
\hline TNB & 1.07 & 93.3 \\
RDX & 0.62 & 112 \\
DNB & 0.18 & 105 \\
TNT & 0.17 & 101 \\
2,4-DNT & 0.26 & 98.4 \\
2,6-DNT & 0.47 & 95.0 \\
2-Am-DNT & 0.63 & 100 \\
4-Am-DNT & 0.99 & 104 \\
\hline
\end{tabular}

without interruption in the flow. Installation of an LC-8 guard column protected the analytical column from the detrimental effects of pressure fluctuation. The end result of this study was selection of an $1100-\mu \mathrm{L}$ injection volume onto the LC-8 column.

\section{Detection}

Detection by UV at $254 \mathrm{~nm}$ has been shown to be a highly sensitive and selective detector for analysis of nitroaromatics and nitramines (Jenkins et al. 1984, 1986, 1988a,b, 1989; Bauer et al. 1986, 1989; Jenkins and Walsh 1987; Miyares and Jenkins 1990; USEPA 1990). UV spectra of each analyte were obtained in the 180 to $330-\mathrm{nm}$ region by stopping the flow as the analyte was passing through the flow cell on the Spectra Physics 8490 detector and scanning at a rate of $1 \mathrm{~nm} / \mathrm{s}$. Since 2,6DNT was the analyte of greatest concern, emphasis was placed on optimizing the operating wavelength for its maximum absorptivity $\left(\lambda_{\max }\right)$. Two $\lambda_{\max }$ values were observed for 2,6-DNT (Fig. 6) in the $\mathrm{H}_{2} \mathrm{O}-\mathrm{MeOH}-\mathrm{THF}$ matrix - a primary $\lambda_{\max }$ at $206 \mathrm{~nm}$ and a secondary $\lambda_{\max }$ at $238 \mathrm{~nm}$. The observed primary $\lambda_{\max }$ is most likely a result of the THF in the matrix, which has a UV cutoff of $212 \mathrm{~nm}$. Previously, we had observed a $\lambda_{\max }$ between 230 and $240 \mathrm{~nm}$ for 2,6-DNT in a MeOH-Water (1:1) matrix, so we chose initially to use $238 \mathrm{~nm}$ as the operating wavelength. However, both laboratory-prepared and field-collected samples produced substantially greater interferences than had been observed in samples analyzed at $254 \mathrm{~nm}$. We then tested $244 \mathrm{~nm}$ as the operating wavelength, but again we observed increased interferences in the chromatograms. Our decision was to use $254 \mathrm{~nm}$ as had been done previously for detection of the analytes of interest.

\section{Certification testing}

A CRL study was carried out as outlined in USATHAMA (1990) for the salting-out preconcentration procedure. A series of five 2-L spiked water samples was prepared at the concentrations ranges listed in Appendix B, Table B2. An aliquot was drawn from each spiked sample and processed through the salting-out extraction-preconcentration procedure as described in the Experimental section. This was repeated on each of four consecutive days as outlined in USATHAMA (1990). CRLs were determined by the method of Hubaux and Vos (1970), also as detailed in USATHAMA (1990). CRL data for the salting-out extraction procedure are presented in Table 13.

\section{Low-concentration direct injecting}

The results of the loop size study indicated the potential for a direct injection, low-concentration screening technique. A CRL study was conducted as described in USATHAMA (1990) using samples prepared as described in the direct injection section of the Experimental section. These samples were an order of magnitude higher in concentration than those for the extracted samples. Resulting CRLs are presented in Table 14. With the exception of 2,4- and 2-6-DNT, the CRLs were all below the current USEPA drinking water criteria. CRLs ranged between 1.7 and 78.3 times higher than those achieved using the original salting-out preconcentration technique. Thus, the preconcentration factor of 152 is not fully realized in the CRL reduction because of the larger random error associated with a more complex analytical technique. Determination of HMX can only be achieved at rather high CRLs because HMX elutes close to the baseline disturbance following injection. This direct injection technique can be used as a screening tool for low concentration determination as well as for quantitation of samples with concentrations near or below $1 \mu \mathrm{g} / \mathrm{L}$ (Table 14). 


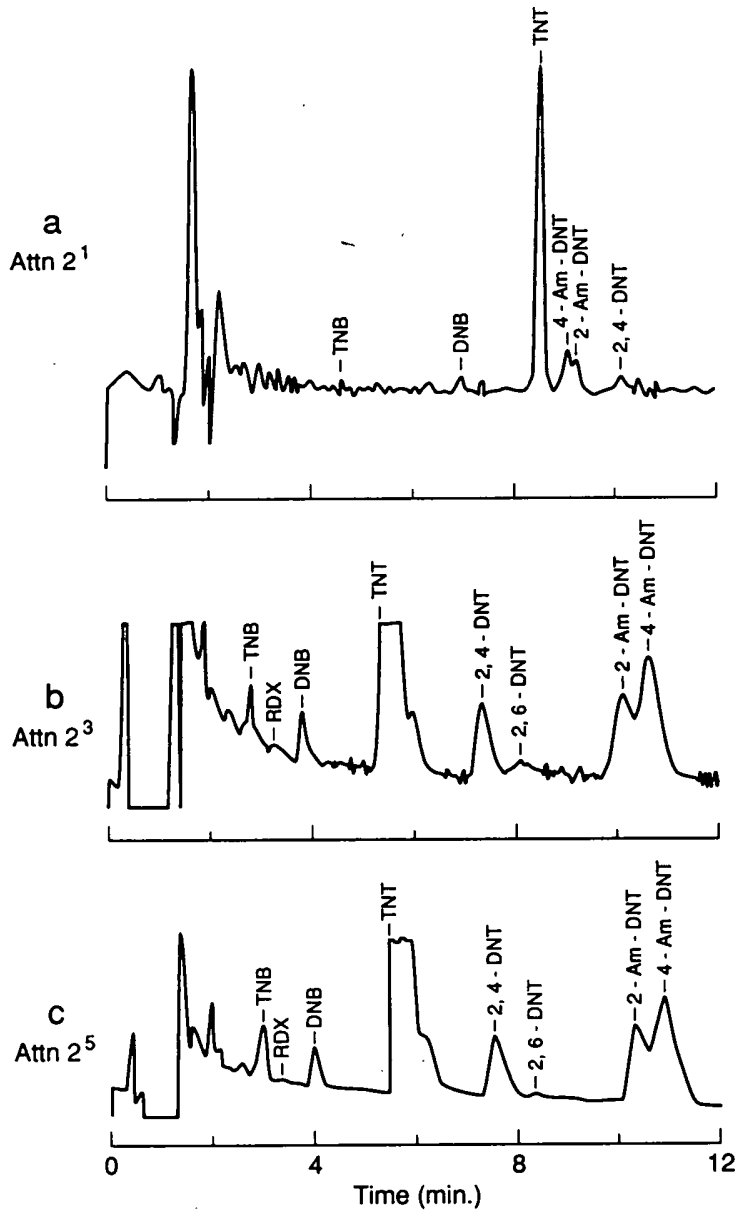

Figure 7. Direct comparison of method capabilities based on separation and detection. Attenuation (Attn n) scale factor $=2^{\mathrm{n}}$.

a. Direct injection method.

Column: $\quad L C-18(25 \mathrm{~cm} \times 4.6 \mathrm{~mm}, 5 \mu \mathrm{m})$

Eluent: $50: 50(v / v) \mathrm{MeOH}-\mathrm{H}_{2} \mathrm{O}$

Flow: $1.5 \mathrm{~mL} / \mathrm{min}$

Detector: $\lambda=254$

Sample injection: $100 \mu \mathrm{L}$.

b. Low level direct injection method.

Column: $\quad L C-8(7.5 \mathrm{~cm} \times 4.6 \mathrm{~mm}, 3 \mu \mathrm{m})$

Eluent: $70.7: 27.8: 1.5(v / v / v)$

$\mathrm{H}_{2} \mathrm{O}-\mathrm{MeOH}-\mathrm{THF}$

Flow: $1.0 \mathrm{~mL} / \mathrm{min}$

Detector: $\lambda=254 \mathrm{~nm}$

Sample injection: $1100 \mu \mathrm{L}$.

c. Improved salting-out extraction method.

Column: $\quad L C-8(7.5 \mathrm{~cm} \times 4.6 \mathrm{~mm}, 3 \mu \mathrm{m})$

Eluent: $\quad 70.7: 27.8: 1.5(v / v / v)$

$\mathrm{H}_{2} \mathrm{O}-\mathrm{MeOH}-\mathrm{THF}$

Flow: $2.0 \mathrm{~mL} / \mathrm{min}$

Detector: $\lambda=254 \mathrm{~nm}$

Sample injection: $1100 \mu \mathrm{L}$.

\section{Analysis of field samples}

The performance of the salting-out extraction procedure was tested using actual groundwater samples from several Army sites. To directly compare the enhanced sensitivity of the method to that of direct injection methods, samples were analyzed by direct injection onto an LC-18 $(25-\mathrm{cm}, 5-\mu \mathrm{m})$ column with UV detection (Jenkins et al. 1988b, USEPA 1990), direct injection of an $1100-\mathrm{mL}$ sample onto the LC-8 $(7.5-\mathrm{cm}, 3-\mu \mathrm{m})$ column with UV detection and by salting-out extraction of a $760-\mathrm{mL}$ sample. Chromatograms from these direct comparisons are presented in Figure 7. Each chromatogram was attenuated (Attn $n$ ) to keep peaks on scale. Attenuation scaling factor is $2^{n}$.

Although unknown compounds were detected in field samples, they did not interfere with the determination of the analytes of interest.

\section{Confirmation separation}

Owing to the potential for interference, we believe it necessary to confirm analyte identities using a second separation. The confirmation separation developed earlier by us (Miyares and Jenkins 1990), employing an LC$8(3.3-\mathrm{cm})$ column in series with an LC-CN $(3.3-\mathrm{cm})$ column eluted with a ternary eluent of water- $\mathrm{MeOH}-$ THF (70.7:27.8:1.5 [v/v/v]) at $1.5 \mathrm{~mL} / \mathrm{min}$ (Fig. 4), was shown to be adequate both for laboratory-prepared samples as well as field-collected samples. Retention times and capacity factors are presented in Table 9.

\section{SUMMARY AND CONCLUSIONS}

A method was developed for the determination of nitroaromatics and nitramines in water that has CRLS that are below the health advisories and water quality criteria set by the USEPA. The method involves extraction of a $760-\mathrm{mL}$ water sample with $248 \mathrm{~g}$ of $\mathrm{NaCl}$ and $170 \mathrm{~mL}$ of $\mathrm{ACN}$ in a 1-L volumetric flask, followed by evaporation and solvent exchange from $A C N$ to water via a Kuderna-Danish concentrator. Samples are introduced on an LC-8 $(7.5-\mathrm{cm}, 3-\mu \mathrm{m})$ column using an $1100-\mathrm{mL}$ sample loop and eluted with an eluent composed of water-MeOH-THF (70.7:27.8:1.5 [v/v/v]) at $2.0 \mathrm{~mL} / \mathrm{min}$. Certified reporting limits range from 6.3 $\mathrm{ng} / \mathrm{L}$ for $2,6-\mathrm{DNT}$ to $271 \mathrm{ng} / \mathrm{L}$ for HMX.

The salting-out extraction-preconcentration procedure takes approximately 2-1/2 hours per sample, but with the exception of the Kuderna-Danish step, the procedure does not require constant monitoring. Also, the number of samples that can be extracted simultaneously is limited only by the availability of laboratory equipment. 


\section{LITERATURE CITED}

Bauer, C.F., C.L. Grant and T.F. Jenkins (1986) Interlaboratory evaluation of high performance liquid chromatographic determination of nitro-organics in munitions plant wastewaters. Analytical Chemistry, 58: 176-182.

Bauer, C.F., T.F. Jenkins, S.M. Koza, P.W. Schumacher, P.H. Miyares and M.E. Walsh (1989) Development of an analytical method for the determination of explosive residues in soil. Part 3. Collaborative test results and final performance evaluation. USA Cold Regions Research and Engineering Laboratory, CRREL Report 89-9.

Belkin, F., R.W. Bishop and M.V. Sheely (1985) Analysis of explosives in water by capillary gas chromatography. Journal of Chromatographic Science, 24: 532-534.

Bicking, M.K.L. and S.J. Summer (1986) Evaluation of solid sorbent and detector technology for determination of explosives in water. Contract No. DAAL03-85D-0001. Columbus, Ohio: Battelle Laboratories.

BUMED (1980) Letter to the Committee on Toxicology, National Research Council. February 11. Washington, D.C.: Bureau of Medicine and Surgery, Department of the Navy, p. 5.

Etnier, E.L. (1987) Water quality criteria for 2,4dinitrotoluene and 2,6-dinitrotoluene. Oak Ridge National Laboratory, ORNL 6312.

Hable, M., C. Stern, C. Asowata and K. Williams (1991) The determination of nitroaromatics and nitramines in ground and drinking water by wide-bore capillary gas chromatography. Journal of Chromatographic Science, 29: 131-135.

Hubaux, A. and G. Vos (1970) Decision and detection limits for linear calibration curves. Analytical Chemistry, 42: 849-855.

Jenkins, T.F. and M.E. Walsh (1987) Development of an analytical method for explosive residues in soil. USA Cold Regions Research and Engineering Laboratory, CRREL Report 87-7.

Jenkins, T.F. and P.H. Miyares (1991) Non-evaporative preconcentration technique for volatile and semivolatile solutes. Analytical Chemistry, 63(13): 13411343.

Jenkins, T.F., C.F. Bauer, D.C. Leggett and C.L. Grant (1984) Reversed-phase HPLC method for analysis of TNT, RDX, HMX and 2,4-DNT in munitions wastewater. USA Cold Regions Research and Engineering Laboratory, CRREL Report 84-29.

Jenkins, T.F. D.C. Leggett, C.L. Grant and C.F. Bauer (1986) Reversed-phase high performance liquid chromatographic determination of nitro-organics in munitions wastewater. Analytical Chemistry, 58: 170-175.
Jenkins, T.F., P.W. Schumacher, M.E. Walsh and C.F.Bauer (1988a) Development of an analytical method for the determination of explosive residues in soil. Part II: Further development and ruggedness testing. USA Cold Regions Research and Engineering Laboratory, CRREL Report 88-8.

Jenkins, T.F., P.H. Miyares and M.E. Walsh (1988b) An improved RP-HPLC method for determining nitroaromatics and nitramines in water. USA Cold Regions Research and Engineering Laboratory, Special Report 88-23.

Jenkins, T.F., M.E. Walsh, P.W. Schumacher, P.H. Miyares, C.F. Bauer and C.L. Grant (1989) Liquid chromatographic method for the determination of extractable nitroaromatic and nitramine residues in soil. Journal of AOAC, 72: 890-899.

Johnson, B.F. and J.G. Dorsey (1990) Solute focusing in flow injection analysis: limits of detection and linear dynamic range. Analytical Chemistry, 62: 1392-1397.

Khanna, K., L. Gordon, W. Hartley, M.E. Brower and W. McLellan (1988-89) Health advisory and ambient water quality criteria for HMX, TNT, and DNT. Washington, D.C.: Criteria and Standards Division, Office of Drinking Water, U.S. Environmental Protection Agency.

Maskarinec, M.P.,D.L.Manning, R.W.Harvey, W.H. Griest and B.A. Tomkins (1984) Determinations of munitions components in water by resin adsorption and high-performance liquid chromatography-electrochemical detection. Journal of Chromatography, 304: 51-63. Miyares, P.H. and T.F. Jenkins (1990) Salting-out solvent extraction method for determining low levels of nitroaromatics and nitramines in water. USA Cold Regions Research and Engineering Laboratory, Special Report 90-30.

National Research Council (NRC) (1982) Evaluation of the health risks of ordnance disposal waste in drinking water. National Research Council, Committee on Toxicology. Washington, D.C.: National Academy Press.

Phillips, J.H., R.J. Coraor and S.R. Prescott (1983) Determination of nitroaromatics in biosludges with gas chromatography/thermal energy analyzer. Analytical Chemistry, 55: 889-892.

Richard, J.J. and G.A. Junk (1986) Determination of munitions in water using macroreticular resins. Analytical Chemistry, 58: 725-727.

Snyder, L.R., J.L. Glajch and J.J. Kirkland (1988) Practical HPLCMethod Development. New York: John Wiley and Son.

Spanggord, R.J., B.W. Gibson, R.G. Keck, D.W. Thomas and J.J. Barkley (1982) Effluent analysis of wastewater generated in the manufacture of 2,4,6-trinitrotoluene. 1. Characterization study. Environmental Science and Technology, 16: 229-232. 
USATHAMA (1990) U. S. Army Toxic and Hazardous Materials Agency Installation Restoration Program. Quality Assurance Program. Aberdeen Proving Ground, Maryland.

U.S. Environmental Protection Agency (USEPA) (1990) Nitroaromatics and nitramines by high-performance liquid chromatography (HPLC) (draft). U.S. Environmental Protection Agency, Method 8330.
Valis, R.J., T.A. Bishop and K.E. Williams (1989) Validation of a sorbent tube/high-performance liquid chromotographic procedure for the determination of eight explosives in water. U.S. Army Environmental Hygiene Agency (AEHA), Aberdeen Proving Ground, Maryland. Walsh, M.E., L.K. Knapp and T.F. Jenkins (1988) Evaluation of disposable membrane filter units for sorptive losses and sample contamination. Environmental Technology Letters, 9: 45-52. 
APPENDIX A: DERIVATION OF EQUATION 1

The following is the derivation of eq 1 used to determine the estimated percent extraction from the volumes of the two phases and the partition coefficient $\left(K_{\mathrm{p}}\right)$ :

$$
\begin{aligned}
& K_{\mathrm{p}}=\frac{C_{\mathrm{s}}}{C_{\mathrm{a}}} \\
& C_{\mathrm{s}}=\frac{M_{\mathrm{s}}}{V_{\mathrm{s}}} \\
& C_{\mathrm{a}}=\frac{M_{\mathrm{a}}}{V_{\mathrm{a}}} \\
& K_{\mathrm{p}}=\frac{M_{\mathrm{s}}}{V_{\mathrm{s}}} \cdot \frac{V_{\mathrm{a}}}{M_{\mathrm{a}}} \\
& M_{\mathrm{a}}=\frac{M_{\mathrm{s}} V_{\mathrm{a}}}{V_{\mathrm{s}} K_{\mathrm{p}}} \\
& M_{\mathrm{T}}=M_{\mathrm{s}}+M_{\mathrm{a}} \\
& \% \text { Extr }=\frac{M_{\mathrm{s}}}{M_{\mathrm{T}}} \times 100 \\
& \% \text { Extr }=\frac{100 M_{\mathrm{s}}}{M_{\mathrm{s}} V_{\mathrm{s}} K_{\mathrm{p}}+M_{\mathrm{s}} V_{\mathrm{a}}} \\
& V_{\mathrm{s}} K_{\mathrm{p}} \\
& \text { Extr }=\frac{100 M_{\mathrm{s}}}{M_{\mathrm{s}}+\frac{M_{\mathrm{s}} V_{\mathrm{a}}}{V_{\mathrm{s}} K_{\mathrm{p}}}} \\
& V_{\mathrm{s}} K_{\mathrm{p}}+V_{\mathrm{a}} \\
& M_{\mathrm{s}} V_{\mathrm{s}} K_{\mathrm{p}}+M_{\mathrm{s}} V_{\mathrm{a}}
\end{aligned}
$$




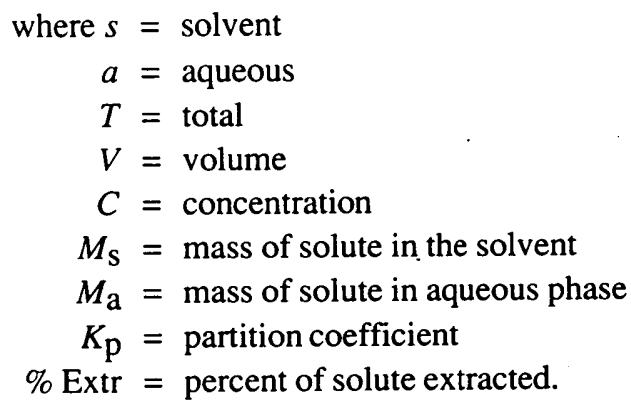




\title{
APPENDIX B: METHOD DOCUMENTATION IN USATHAMA (1990) FORMAT
}

\author{
Precertification Calibration \\ Improved Salting-Out Solvent Extraction Method for \\ Determination of Low Levels of Nitroaromatics and Nitramines \\ in Ground Water
}

\section{Summary}

A. Analytes: The following analytes can be determined using this analytical method: HMX, RDX, 135TNB, 13DNB, NB, 246TNT, 24DNT, 26DNT, 4NT, 2ADNT and 4ADNT.

B. Matrix: This method is suitable for the determination of nitroaromatics and nitramines in ground and surface water.

C. General method: This method involves the sequential extraction of a $760-\mathrm{mL}$ water sample by the addition of $248 \mathrm{~g}$ of $\mathrm{NaCl}$ and two aliquots of acetonitrile (ACN) $(170+10 \mathrm{~mL})$. Upon phase separation, the ACN phase is collected and the volume reduced to less than $0.5 \mathrm{~mL}$ by means of a Kuderna-Danish microconcentrator. The sample is then diluted to $5.0 \mathrm{~mL}$ with water. Determination is by reversed-phase HPLC on an LC- $8(7.5 \mathrm{~cm} \times 4.6 \mathrm{~mm}, 3 \mu \mathrm{m})$ column preceded by an LC- 8 guard column and eluted with a ternary eluent of 70.7:27.8:1.5 (v/v/v) water-methanol-tetrahydrofuran at $2.0 \mathrm{~mL} / \mathrm{min}$. Analyte confirmation is obtained on an LC-8 $(3.3 \mathrm{~cm} \times 4.6 \mathrm{~mm}, 3 \mu \mathrm{m})$ column in series with an $\mathrm{LC}=\mathrm{CN}(3.3 \mathrm{~cm} \times 4.6 \mathrm{~mm}, 3 \mu \mathrm{m})$ column eluted with the same eluent as the primary separation at a flow rate of $1.5 \mathrm{~mL} / \mathrm{min}$. Samples are introduced onto the column using an $1100-\mu \mathrm{L}$ sample loop and detection of analytes is by UV at $254 \mathrm{~nm}$.

\section{Application}

A. Calibration range: The linear calibration range for each analyte for this method is shown in Table B1.

B. Tested concentration range: The range of each analyte concentration over which this method was tested is shown in Table B2.

C. Sensitivity: The response of the UV detector at $254 \mathrm{~nm}$ for each analyte is presented in Table B3.

D. Interferences: While baseline separation is not achieved for 2ADNT and 4ADNT, resolution is sufficient so that the two can be determined simultaneously if present at similar concentrations. HMX may be determined using this method if the concentration is above $1 \mu \mathrm{g} / \mathrm{L}$. HMX elutes on the down slope of the baseline disturbance introduced by the salt in the sample. EPA monitoring requirements for $\mathrm{HMX}$ are $1.8 \mathrm{mg} / \mathrm{L}$ (McLellan et al. 1988), which can easily be met using this method. The retention times for the certified analytes as well as potential interferences for the primary and confirmatory separations are presented in Table B4. The LC-8/LC-CN series of columns is satisfactory for confirmation of the primary analytes. $\mathrm{NaCl}$ must be reagent grade or better and must have been obtained and stored in glass bottles only. Plastic containers introduce interfering compounds.

E. Safety information: The normal safety precautions appropriate to use of flammable organic solvents should be employed.

\section{Apparatus and Chemicals}

\section{A. Instrumentation:}

1. HPLC system: Spectra Physics HPLC SP8810 pump (or equivalent), an injector equipped with an $1100-\mu \mathrm{L}$ injection loop and a Spectra Physics SP8490 UV detector set to $254 \mathrm{~nm}$ and equipped with 
a 1.0-cm cell path length (or equivalent variable wavelength or fixed 254-nm detector). The primary analytical column (LC-8) is eluted with ternary eluent composed of water-methanol-tetrahydrofuran $(70.7: 27.8: 1.5[\mathrm{v} / \mathrm{v} / \mathrm{v}])$ at $2.0 \mathrm{~mL} / \mathrm{min}$. The confirmation columns $(\mathrm{LC}-8 / \mathrm{LC}-\mathrm{CN})$ are eluted with the same eluent at $1.5 \mathrm{~mL} / \mathrm{min}$.

2. Strip chart recorder (Linear 500 or equivalent).

3. Digital Integrator (HP 3393A or equivalent) equipped with an external disk drive (HP 9114B or equivalent).

4. LC-8 (Supelco) RP-HPLC column, $7.5 \mathrm{~cm} \times 4.6 \mathrm{~mm}(3 \mu \mathrm{m})$.

5. LC-CN (Supelco) RP-HPLC column, $3.3 \mathrm{~cm} \times 4.6 \mathrm{~mm}(3 \mu \mathrm{m})$.

6. LC-8 (Supelco) RP-HPLC column, $3.3 \mathrm{~cm} \times 4.6 \mathrm{~mm}(3 \mu \mathrm{m})$.

7. LC-8 (supelco) RP-HPLC guard column $(5 \mu \mathrm{m})$.

8. Syringe (Hamilton), glass, $5 \mathrm{~mL}$, Teflon capped plunger, Luerlok equipped with adaptor needle for Rheodyne injection value.

B. Analytes:

1. HMX (octahydro-1,3,5,7-tetranitro-1,3,5,7-tetrazocine)

BP: decomposes

MP: $282^{\circ} \mathrm{C}$

Solubility in water at $22.5^{\circ} \mathrm{C}: 5.0 \mu \mathrm{g} / \mathrm{L}$

Octanol/water partition coefficient: 1.3

CAS \#2691-41-0.

2. RDX (hexahydro-1,3,5-trinitro-1,3,5-triazine)

BP: decomposes

MP: $203.5^{\circ} \mathrm{C}$

Solubility in water at $25^{\circ} \mathrm{C}: 60 \mathrm{mg} / \mathrm{L}$

Octanol/water partition coefficient: 7.5

CAS \#121-82-4.

3. 135TNB (1,3,5-trinitrobenzene)

BP: decomposes

MP: $122^{\circ} \mathrm{C}$

Solubility in water at $25^{\circ} \mathrm{C}: 385 \mathrm{mg} / \mathrm{L}$

Octanol/water partition coefficient: 15

CAS \#99-35-4.

4. 13DNB (1,3-dinitrobenzene)

BP: $302^{\circ} \mathrm{C}$

MP: $122^{\circ} \mathrm{C}$

Solubility in water at $25^{\circ} \mathrm{C}: 533 \mathrm{mg} / \mathrm{L}$

Octanol/water partition coefficient: 31

CAS \#99-65-0.

5. NB (nitrobenzene)

BP: $211^{\circ} \mathrm{C}$ (flashpoint $88^{\circ} \mathrm{C}$ )

MP: $5.7^{\circ} \mathrm{C}$

Solubility in water: $2 \mathrm{~g} / \mathrm{L}$

Octanol/water partition coefficient: 71

CAS \#98-95-3.

6. 246TNT (2,4,6-trinitrotoluene)

BP: $280^{\circ} \mathrm{C}$ (explodes)

MP: $80.1^{\circ} \mathrm{C}$

Solubility in water: $130 \mathrm{mg} / \mathrm{L}$

Octanol/water partition coefficient: 68

CAS \#118-96-7. 
7. 24DNT (2,4-dinitrotoluene)

BP: $300^{\circ} \mathrm{C}$ (decomposes)

MP: $70^{\circ} \mathrm{C}$

Solubility in water: $300 \mathrm{mg} / \mathrm{L}$

Octanol/water partition coefficient: 95

CAS \#121-14-2.

8. 26DNT (2,6-dinitrotoluene)

MP: $66^{\circ} \mathrm{C}$

Solubility in water $\left(25^{\circ} \mathrm{C}\right): 206 \mathrm{mg} / \mathrm{L}$

Octanol/water partition coefficient: 97

CAS \#606-20-2.

9. 4NT (para-nitrotoluene)

BP: $238^{\circ} \mathrm{C}$

MP: $54^{\circ} \mathrm{C}$

Octanol/water partition coefficient: 202

CAS\# 99-99-0.

10. 2ADNT (2-amino-4,6-dinitrotoluene)

MP: $173-174^{\circ} \mathrm{C}$

Octanol/water partition coefficient: $88.2^{*}$

CAS \#35572-78-2.

11. 4ADNT (4-amino-2,6-dinitrotoluene)

MP: $171-172^{\circ} \mathrm{C}$

Octanol/water partition coefficient: $81.5^{*}$

CAS \#1946-51-0.

C. Reagents and SARMs:

1. HMX-SARM quality.

2. RDX-SARM quality.

3. 135TNB-SARM quality.

4. 13DNB-SARM quality.

5. NB-SARM quality.

6. 246TNT-SARM quality.

7. 24DNT-SARM quality.

8. 26DNT-SARM quality.

9. 4NT-reagent grade.

10. 2ADNT-reagent grade.

11. 4ADNT-reagent grade.

12. Methanol-HPLC grade.

13. Water-reagent grade.

14. Acetonitrile-HPLC grade.

15. Tetrahydrofuran-HPLC grade.

\section{Precertification Calibration}

A. Preparation of standards: Solid material (SARM or reagent grade) for each analyte was dried to constant weight in a vacuum desiccator in the dark. Approximately $0.250 \mathrm{~g}(250 \mathrm{mg})$ of each dried SARM or dried reagent was weighed out to the nearest $0.1 \mathrm{mg}$ and transferred to individual $250-\mathrm{mL}$ volumetric flasks and diluted to volume with HPLC grade ACN. Stock standards are stored in a refrigerator at $4^{\circ} \mathrm{C}$ in the dark and are usable for a period up to 1 year after the date of preparation. The concentration of each stock standard is presented in Table B5.

* Estimated (Jenkins 1989). 
Two identical combined analyte stock solutions labeled $X$ and $X X$ are prepared by combining 1.00 $\mathrm{mL}$ of each of these analyte stock standards: HMX, RDX, 135TNB, 13DNB, NB, 246TNT, 24DNT, 26DNT, 4NT, 2ADNT and 4ADNT in a 100-mL volumetric flask and diluted to volume in water. The analyte concentration in solutions $\mathrm{X}$ and $\mathrm{XX}$ are presented in Table B6. A series of precertification standard solutions is prepared from each of the combined stock solutions $\mathrm{X}$ and $\mathrm{XX}$ following the dilutions presented in Table B7. These solutions are labeled A through $\mathrm{H}$ and AA through $\mathrm{HH}$ respectively. All dilutions are in $100-\mathrm{mL}$ volumetric flasks and are diluted to volume with water. Concentrations of the analytes in the precertification calibration solutions are presented in Table B6.

B. Instrument calibration: No dilution of the precertification calibration standards with solvent is required prior to the analysis. The precertification calibration standards are analyzed singly in random order. The acceptability of a linear model for each analyte is assessed using the protocol specified in the USATHAMA QA Program (1990). Experience has shown that a linear model with a zero intercept is appropriate. Therefore, the response factor for each analyte is taken to be the slope of the best fit regression line.

\section{Procedure}

A. Separation: Primary analysis is obtained by RP-HPLC employing an LC- $8(7.5 \mathrm{~cm} \times 4.6 \mathrm{~mm}$, $3 \mu \mathrm{m}$ ) column preceded by an LC- 8 guard column eluted with a ternary eluent composed of 70.7:27.8:1.5 (v/v/v) water-MeOH-THF at $2.0 \mathrm{~mL} / \mathrm{min}$. Retention times and capacity factors for the separation are found in Table B4. A chromatogram of the separation is shown in Figure B1. Confirmation analysis is obtained by employing an LC-8 $(3.3 \mathrm{~cm} \times 4.6 \mathrm{~mm}, 3 \mu \mathrm{m})$ column in series with an LC-CN $(3.3 \mathrm{~cm} \times 4.6 \mathrm{~mm}, 3 \mu \mathrm{m})$ column preceded by an LC-8 guard column and eluted with the same eluent as the primary separation at a flow rate of $1.5 \mathrm{~mL} / \mathrm{min}$ (Jenkins et al., 1988). A chromatogram of the separation is shown in Figure B2.

B. Instrumental analysis: Samples are introduced onto the column by means of an injection valve equipped with an $1100-\mu \mathrm{L}$ sample loop. The loop is flushed with $2.5 \mathrm{~mL}$ of sample using a $5-\mathrm{mL}$ glass syringe. Detection is by UV at $254 \mathrm{~nm}$. Peak height determination is by digital integration.

\section{Calculation}

To obtain a precertification calibration curve for each analyte, the protocol for precertification outlined in USATHAMA QA Program (1990) is employed.

\section{References}

1. Jenkins, T.F. (1989) Development of an analytical method for the determination of extractable nitroaromatics and nitramines in soil. Ph.D. dissertation, University of New Hampshire.

2. Jenkins, T.F., P.H. Miyares and M.E. Walsh (1988) An improved RP-HPLC method for determining nitroaromatics and nitramines in water. USA Cold Regions Research and Engineering Laboratory, Special Report 88-23.

3. McLellan, W., W.R. Hartley and M. Brower (1988) Health advisory for octahyhro-1,3,5,7-tetranitro1,3,5,7-tetrazocine. Office of Drinking Water, U.S. Environmental Protection Agency, Washington, D.C.

4. USATHAMA (1990) USA Toxic and Hazardous Materials Agency Installation Restoration Program, Quality Assurance Program. Aberdeen Proving Ground, Maryland. 


\section{Certification \\ Improved Salting-Out Solvent Extraction Method for \\ Determination of Low Levels of Nitroaromatics and Nitramines \\ in Ground Water}

\section{Summary}

A. Analytes: The following analytes can be determined using this analytical method: HMX, RDX, 135TNB, 13DNB, NB, 246TNT, 24DNT, 26DNT, 4NT, 2ADNT and 4ADNT.

B. Matrix: This method is suitable for the determination of nitroaromatics and nitramines in ground and surface water.

C. General method: This method involves the extraction of a $760-\mathrm{mL}$ water sample by the addition of $248 \mathrm{~g}$ of $\mathrm{NaCl}$ and $170 \mathrm{~mL}$ of acetonitrile $(\mathrm{ACN})$ followed by a second extraction with an additional $10 \mathrm{~mL}$ of $\mathrm{ACN}$. The ACN from the two extractions is combined and the volume reduced to less than $0.5 \mathrm{~mL}$ using a Kuderna-Danish microconcentrator. The sample is diluted to a volume of approximately $2 \mathrm{~mL}$ with water, then combined with an additional $3 \mathrm{~mL}$ of water. Primary determination is obtained by reversed-phase (RP) high performance liquid chromatography (HPLC) using an LC-8 (7.5 $\mathrm{cm} \times 4.6 \mathrm{~mm}, 3 \mu \mathrm{m}$ ) column preceded by an LC-8 guard column. A ternary eluent composed of 70.7:27.8:1.5 (v/v/v) of water-methanol-tetrahydrofuran is used at a flow rate of $2.0 \mathrm{~mL} / \mathrm{min}$. Detection is by UV at $254 \mathrm{~nm}$. Analytes identified in the primary analysis are confirmed using an LC$8(3.3 \mathrm{~cm} \times 4.6 \mathrm{~mm}, 3 \mu \mathrm{m})$ column in series with an LC-CN $(3.3 \mathrm{~cm} \times 4.6 \mathrm{~mm}, 3 \mu \mathrm{m})$ column preceded by an LC- 8 guard column and eluted with the same eluent as the primary separation at $1.5 \mathrm{~mL} / \mathrm{min}$.

\section{Application}

A. Tested concentration range: The range of each analyte concentration over which this method was tested is shown in Table B2.

B. Sensitivity: The response of the UV detector at $254 \mathrm{~nm}$ for each analyte is presented in Table B3.

C. Reporting limits: Certified Reporting Limits (CRL) for the following analytes were determined over a four-day period using the method of Hubaux and Vos (1970) as described in the USATHAMA Installation Restoration Program Quality Assurance Program (1990). CRL values for the analytes are presented in Table B8.

D. Interferences: While baseline separation is not achieved for 2ADNT and 4ADNT, resolution is sufficient so that the two can be determined simultaneously. HMX may be determined using this method if the concentration is above $1 \mu \mathrm{g} / \mathrm{L}$. HMX elutes on the down slope of the baseline disturbance introduced by the salt in the sample. EPA monitoring requirements for $\mathrm{HMX}$ are $1.8 \mathrm{mg} / \mathrm{L}$ (McLellan, 1988 ), which can easily be met using this method. The retention times for the certified analytes as well as potential interferences for the LC- 8 and LC-8/LC-CN separations are presented in Table B4. The LC-8/LC-CN series of columns was shown to be satisfactory for confirmation of the primary analytes.

Sodium chloride used in the extraction step must be reagent grade or better and must have been obtained and stored in glass bottles only. Plastic containers can introduce interfering compounds.

E. Analysis rate: In an 8-hour work day, 10 samples can be processed and analyzed along with appropriate calibration standards.

F. Safety information: The normal safety precautions appropriate to use of flammable organic solvents, hot plates and preconcentrators should be employed.

\section{Apparatus and Chemicals}

\section{A. Glassware/hardware:}

1. Volumetric flasks: $2000 \mathrm{~mL}$ (6), $1000 \mathrm{~mL}$ (1/sample), $500 \mathrm{~mL}$ (1), $200 \mathrm{~mL}$ (1), $100 \mathrm{~mL}$ (6).

2. Volumetric pipettes: $100 \mathrm{~mL}(1), 50 \mathrm{~mL}$ (1), $25 \mathrm{~mL}$ (1), $20 \mathrm{~mL}$ (2), $10 \mathrm{~mL}$ (6), $5 \mathrm{~mL}$ (4), $4 \mathrm{~mL}$ (1), $3 \mathrm{~mL}$ (1), $2 \mathrm{~mL}(2), 1 \mathrm{~mL}(10)$. 
3. Magnetic stirring plate ( $1 /$ sample).

4. Magnetic stirring bar, $1-1 / 2$ to 2 in. long ( $1 /$ sample).

5. Teflon capped vial: $40 \mathrm{~mL}$, glass (1/clear sample) (2/turbid sample).

6. Scintillation vials: $20 \mathrm{~mL}$, glass (1/sample).

7. Powder funnel: glass (1).

8. Balance: accuracy $( \pm 0.01 \mathrm{~g})$, capacity $(>300 \mathrm{~g})$.

9. Kuderna-Danish microconcentrators: $2.0-\mathrm{mL}$ receiving vessel, $40-\mathrm{mL}$ flask, $10-\mathrm{cm}$ distillation column ( $1 /$ sample).

10. Centrifuge: capacity for $40-\mathrm{mL}$ vial, speed minimum $4000 \mathrm{rpm}$.

11. Syringe (Hamilton) glass, $5 \mathrm{~mL}$, Teflon capped plunger, Luerlok equipped with an adaptor needle for Rheodyne injection valve.

12. Disposable filter unit: Millex SR $0.5 \mu \mathrm{m}$.

\section{B. Instrumentation:}

1. HPLC System: HPLC Spectra Physics SP8810 pump (or equivalent), an injector equipped with an 1100- $\mu$ L injection loop and a Spectra Physics SP8490 UV detector set to $254 \mathrm{~nm}$ and equipped with a $1-\mathrm{cm}$ path flow cell (or equivalent variable wavelength or fixed $254-\mathrm{nm}$ detector). The RPHPLC column is eluted with an eluent composed of water-methanol-tetrahydrofuran (70.7:27.8:1.5 $[\mathrm{v} / \mathrm{v} / \mathrm{v}])$ at $2.0 \mathrm{~mL} / \mathrm{min}$. The confirmation columns $(\mathrm{LC}-8 / \mathrm{LC}-\mathrm{CN})$ are eluted with the same eluent at $1.5 \mathrm{~mL} / \mathrm{min}$.

2. Strip chart recorder (Linear 500 or equivalent).

3. Digital Integrator (HP3393A or equivalent) equipped with an external disk drive (HP9114B or equivalent).

4. LC-8 (Supelco) RP-HPLC column, $7.5 \mathrm{~cm} \times 4.6 \mathrm{~mm}(3 \mu \mathrm{m})$.

5. LC-8 (Supelco) RP-HPLC column, $3.3 \mathrm{~cm} \times 4.6 \mathrm{~cm}(3 \mu \mathrm{m})$.

6. LC-CN (Supelco) RP-HPLC column, $3.3 \mathrm{~cm} \times 4.6 \mathrm{~mm}(3 \mu \mathrm{m})$.

7. LC-8 (Supelco) guard column $(5 \mu \mathrm{m})$.

\section{Analytes:}

1. HMX (octahydro-1,3,5,7-tetranitro-1,3,5,7-tetrazocine)

BP: decomposes

MP: $282^{\circ} \mathrm{C}$

Solubility in water at $22.5^{\circ} \mathrm{C}: 5.0 \mu \mathrm{g} / \mathrm{L}$

Octanol/water partition coefficient: 1.3

CAS \#2691-41-0.

2. RDX (hexahydro-1,3,5-trinitro-1,3,5-triazine)

BP: decomposes

MP: $203.5^{\circ} \mathrm{C}$

Solubility in water at $25^{\circ} \mathrm{C}: 60 \mathrm{mg} / \mathrm{L}$

Octanol/water partition coefficient: 7.5

CAS \#121-82-4.

3. 135TNB (1,3,5-trinitrobenzene)

BP: decomposes

MP: $122^{\circ} \mathrm{C}$

Solubility in water at $25^{\circ} \mathrm{C}: 385 \mathrm{mg} / \mathrm{L}$

Octanol/water partition coefficient: 15

CAS \#99-35-4.

4. 13DNB (1,3-dinitrobenzene)

BP: $302^{\circ} \mathrm{C}$

MP: $122^{\circ} \mathrm{C}$

Solubility in water at $25^{\circ} \mathrm{C}: 533 \mathrm{mg} / \mathrm{L}$

Octanol/water partition coefficient: 31 
CAS \#99-65-0.

5. NB (nitrobenzene)

BP: $211^{\circ} \mathrm{C}$ (flashpoint, $88^{\circ} \mathrm{C}$ )

MP: $5.7^{\circ} \mathrm{C}$

Solubility in water: $2 \mathrm{~g} / \mathrm{L}$

Octanol/water partition coefficient: 71

CAS \# 98-95-3.

6. 246TNT (2,4,6-trinitrotoluene)

BP: $280^{\circ} \mathrm{C}$ (explodes)

MP: $80.1^{\circ} \mathrm{C}$

Solubility in water: $130 \mathrm{mg} / \mathrm{L}$

Octanol/water partition coefficient: 68

CAS \#118-96-7.

7. 24DNT (2,4-dinitrotoluene)

BP: $300^{\circ} \mathrm{C}$ (decomposes)

MP: $70^{\circ} \mathrm{C}$

Solubility in water: $300 \mathrm{mg} / \mathrm{L}$

Octanol/water partition coefficient: 95

CAS \#121-14-2.

8. 26DNT (2,6-dinitrotoluene)

MP: $66^{\circ} \mathrm{C}$

Solubility in water $\left(25^{\circ} \mathrm{C}\right): 206 \mathrm{mg} / \mathrm{L}$

Octanol/water partition coefficient: 97

CAS \#606-20-2.

9. 4NT (para-nitrotoluene)

BP: $238^{\circ} \mathrm{C}$

MP: $54^{\circ} \mathrm{C}$

Octanol/water partition coefficient: 202

CAS \# 99-99-0.

10. 2ADNT (2-amino-4,6-dinitrotoluene)

MP: $173^{\circ}-174^{\circ} \mathrm{C}$

Octanol/water partition coefficient: 88.2 *

CAS \#35572-78-2.

11. 4ADNT (4-amino-2,6-dinitrotoluene)

MP: $171^{\circ}-172^{\circ} \mathrm{C}$

Octanol/water partition coefficient: $81.5^{*}$

CAS \#1946-51-0.

D. Reagents and SARMs

1. HMX-SARM quality.

2. RDX-SARM quality.

3. 135TNB-SARM quality.

4. 13DNB-SARM quality.

5. NB-SARM quality.

6. 246TNT-SARM quality.

7. 24DNT-SARM quality.

8. 26DNT-SARM quality.

9. 4NT-reagent grade.

10. 2ADNT—reagent grade.

* Estimated (Jenkins 1989). 
11. 4ADNT-reagent grade.

12. $\mathrm{NaCl}$-reagent grade.

13. ACN-HPLC grade.

14. Methanol-HPLC grade.

15. Water-reagent grade.

16. THF-HPLC grade.

\section{Calibration}

\section{A. Initial calibration:}

1. Preparation of standards: Analyte material (SARM or reagent grade) was dried to constant weight in a vacuum desiccator in the dark. Approximately $0.250 \mathrm{~g}(250 \mathrm{mg})$ of each dried SARM or dried reagent was weighed out to the nearest $0.1 \mathrm{mg}$, transferred to individual $250-\mathrm{mL}$ volumetric flasks, diluted to volume with HPLC grade $\mathrm{ACN}$ and stored in a refrigerator at $4^{\circ} \mathrm{C}$ in the dark. Stock standards are usable for a period up to 1 year after the date of preparation. The concentration of each stock standard is presented in Table B5.

A combined analyte stock solution labeled $\mathrm{N}$ is prepared by combining $1.0 \mathrm{~mL}$ each of the $\mathrm{HMX}$, RDX, 135TNB, 13DNB, NB, 246TNT, 24DNT, 26DNT, 4NT, 2ADNT and 4ADNT analyte stock standards in a $100-\mathrm{mL}$ volumetric flask and diluting to volume with water. The analyte concentrations for solution $\mathrm{N}$ are presented in Table B9. A series of calibration standards is prepared as described Table B10 and labeled $\mathrm{P}$ through $\mathrm{UV}$ respectively. All dilutions are made in 100 -mL volumetric flasks and brought to volume with water.

2. Instrumental calibration: No further dilution of the standards with solvent is required for analysis. The calibration standards are analyzed in duplicate in random order.

3. Acceptability of a linear model: For each analyte, this is assessed using the protocol specified in the USATHAMA QA Program (1990). Experience has shown that a linear model with a zero intercept is appropriate. The response factor is the slope of the best fit, zero intercept linear regression line.

B. Daily calibration:

1. Preparation of standards: Stock standards for each analyte are prepared in an identical manner to that described for the initial calibration above. The concentrations of the individual stock standards are presented in Table B11. A combined analyte standard solution labeled NN is prepared using a three-step process. First, combine $5.00 \mathrm{~mL}$ each of the 24DNT and 26DNT individual stock standards, plus $10.0 \mathrm{~mL}$ each of the 246TNT, 2ADNT and 4ADNT individual stock standards in a 200$\mathrm{mL}$ volumetric flask and dilute to volume with $\mathrm{ACN}$. Second, combine in a 100 -mL volumetric flask, $10.0 \mathrm{~mL}$ each of the 13DNB and 135TNB individual stock standards plus $2.00 \mathrm{~mL}$ of the 4NT individual stock standard and dilute to volume with ACN. Finally, prepare solution NN in a $500-\mathrm{mL}$ volumetric flask by combining $10.0 \mathrm{~mL}$ of the solution from the first step, $25.0 \mathrm{~mL}$ of the solution from the second step, add $5.00 \mathrm{~mL}$ each of the HMX, RDX and NB individual stock standards and dilute to volume with $\mathrm{ACN}$. The concentration of each analyte in solution $\mathrm{NN}$ is presented in Table B11. The daily calibration standard solution labeled PP is prepared by diluting $1.00 \mathrm{~mL}$ of standard solution NN in a $100-\mathrm{mL}$ volumetric flask with water. The concentration of daily calibration solution PP is presented in Table B11. The combined analyte calibration solution (NN) is stored in a refrigerator at $4^{\circ} \mathrm{C}$ in the dark and is usable for a period of up to 28 days. The daily calibration standard (PP) must be prepared daily.

2. Instrumental analysis: The daily calibration standard solution, PP, is $99 \%$ aqueous. Owing to the nature of the separation, dilution with a solvent is not required. This standard solution is analyzed in triplicate at the beginning of each day of analysis, singly at the mid-point and singly at the end of each day of analysis. Response factors for each analyte are obtained from the mean peak height and compared with the response factors obtained in the initial calibration.

3. Response factor: The mean response factor for the daily calibration must agree within $\pm 25 \%$ of the response factor of the initial calibration for the first seven daily calibrations and within two 
standard deviations of the initial calibration for subsequent calibrations. If the criteria are not met, a new initial calibration must be obtained.

\section{Certification Testing}

A. Preparation of spiking standards: Individual analyte certification stock standards are prepared in the identical manner as described for the calibration stock standards above. A combined analyte certification solution labeled $\mathrm{QQ}$ is prepared using the three step procedure outlined for the combined analyte calibration stock solution (NN) above. The analyte concentrations in solution QQ are presented in Table B12. A series of spiking certification solutions is prepared from solution QQ in the manner outlined in Table B13. All dilutions are made in $100-\mathrm{mL}$ volumetric flasks in ACN. Concentrations of analytes in the spiking solutions are presented in Table B12. Certification stocks, combined and spiking solutions are stored in a refrigerator at $4^{\circ} \mathrm{C}$ in the dark. Stock solutions are usable up to 1 year after date of preparation. Combined solutions and spiking solutions are usable for up to 28 days.

B. Preparation of certification samples: Certification samples are prepared by diluting $1.00 \mathrm{~mL}$ of each of the certification spiking solutions RR-UV to $2000 \mathrm{~mL}$ in water each in individual $2000-\mathrm{mL}$ volumetric flasks. The certification blank sample is prepared by diluting $1.00 \mathrm{~mL}$ of ACN to $2000 \mathrm{~mL}$ in water in a volumetric flask. A $760-\mathrm{mL}$ aliquot of each certification sample solution and the certification blank solution are measured in graduated cylinders and transferred to individual 1000$\mathrm{mL}$ volumetric flasks and samples are extracted as described below for real samples.

\section{Procedure}

A. Preparation of sample: A $760-\mathrm{mL}$ volume of a water sample is measured in a graduated cylinder and transferred to a $1000-\mathrm{mL}$ volumetric flask. A $248-\mathrm{g}$ sample of $\mathrm{NaCl}$ is added to the water sample. A magnetic stir bar is placed in the flask and the sample placed on a magnetic stirring plate and stirred vigorously until the $\mathrm{NaCl}$ is completely dissolved. Upon dissolution of the salt, $170 \mathrm{~mL}$ of $A C N$ is pipetted slowly into the stirring sample solution, allowing the $A C N$ to mix into the solution and avoiding overflow of the flask. Upon complete addition of the $\mathrm{ACN}$, the speed of the stirring plate is adjusted to ensure that the entire $\mathrm{ACN}$ phase is drawn down into the aqueous phase during the extraction. The samples are stirred for approximately 30 minutes. Samples are then allowed to stand approximately 30 minutes to achieve phase separation.

Upon phase separation, the $\mathrm{ACN}$ phase is removed by means of a Pasteur pipette and transferred to a 40-mL Teflon capped vial. An additional $10 \mathrm{~mL}$ aliquot of $\mathrm{ACN}$ is added to the sample in the volumetric flask. The sample is again stirred for approximately 30 minutes, and allowed to stand approximately 30 minutes. The second ACN extract is combined with the first extract in the Teflon capped vial. If the collected extract is turbid, the sample is centrifuged at $4000 \mathrm{rpm}$ for 5 minutes. The $\mathrm{ACN}$ extract is then drawn off the centrifuged sample by Pasteur pipette and transferred to a clean 40$\mathrm{mL}$ vial. The ACN extract is examined for large water drops. If any are present, they are removed with a Pasteur pipette.

The ACN sample extract is transferred to a Kuderna-Danish microconcentrator and the volume reduced to less than $0.5 \mathrm{~mL}$. The sample is then taken up in $2.0 \mathrm{~mL}$ of water. The sample is allowed to reflux for 2 to 5 minutes to allow further evaporation of $\mathrm{ACN}$. The $2.00-\mathrm{mL}$ water sample is removed from the Kuderna-Danish device and combined with $3.00 \mathrm{~mL}$ of fresh water in a scintillation vial. The sample is shaken, then poured back into the Kuderna-Danish device to rinse the sides of the glassware. The sample is then returned to the scintillation vial. If the sample is cloudy, it is filtered through a Millex SR, $0.5-\mu \mathrm{m}$ disposable filter, collecting all $5 \mathrm{~mL}$ of filtrate. No further dilution of the sample is necessary for analysis.

B. Determination: Determination of the analyte concentration in the sample solution is obtained by RP-HPLC-UV at $254 \mathrm{~nm}$. A $2.5-\mathrm{mL}$ aliquot of sample is used to overfill an $1100-\mu \mathrm{L}$ sample loop. The LC-8 column and LC-8 guard column are eluted with a ternary eluent composed of water-MeOHTHF $(70.7: 27.8: 1.5[\mathrm{v} / \mathrm{v} / \mathrm{v}])$ at $2.0 \mathrm{~mL} / \mathrm{min}$. Retention times and capacity factors for the analytes of 
interest as well as a number of potential interfering compounds are presented in Table B4. Confirmation separation is performed using a two-column sequence of LC-8 followed by LC-CN, which are preceded by an LC- 8 guard column and eluted with the same eluent at $1.5 \mathrm{~mL} / \mathrm{min}$. Retention times and capacity factors for both separations are presented in Table B4. Chromatograms for the primary (LC-8) and confirmatory (LC-8/LC-CN) separations of the analytes of interest are shown in Figures $B 1$ and $B 2$, respectively.

\section{Calculation}

A. Response factors: Since a linear calibration curve with zero intercept is to be expected, calculations of daily results are obtained using response factors calculated for each analyte. The mean response $(\bar{R})$ for each analyte from repeated determinations of the daily calibration solution (PP) is obtained in peak height units. The response factor $(R F)$ for each analyte is obtained by dividing the mean response by the known concentration $(C)$ in units of $\mu \mathrm{g} / \mathrm{L}$

$$
R F=\frac{\bar{R}}{C} \text {. }
$$

B. Analyte concentration: The concentrations $(\mu \mathrm{g} / \mathrm{L})$ of each analyte $\left(C_{\mathrm{a}}\right)$ are obtained by dividing the response for each analyte $\left(R_{\mathrm{a}}\right)$ by the appropriate response factor $\left(R F_{\mathrm{a}}\right)$, then dividing by the preconcentration factor of 152 . Preconcentration factor $(P F)$ is the ratio of the initial sample volume $(760 \mathrm{~mL})$ over the final sample volume $(5 \mathrm{~mL})$.

$$
\begin{aligned}
& P F=\frac{760}{5}=152 . \\
& C_{\mathrm{a}}=\frac{R_{\mathrm{a}}}{R F_{\mathrm{a}}} \div 152 .
\end{aligned}
$$

\section{Daily Quality Control}

A. Control spikes: Spiked water samples are prepared as described for the Class 1 method in the USATHAMA QA Program (1990). This requires the use of a method blank, a single spike at two times the certified reporting limit and duplicate spikes at ten times the certified reporting limit for each analytical lot. Control spikes are prepared using the appropriate spiking solution in an identical manner as described in Section V.

B. Control charts: The control charts required are described for Class 1 methods in USATHAMA QA Program (1990). This will require use of standard Shewhart X and $R$ charts for the duplicate high spike (Table B14a) and moving average X and $R$ charts for the single low spike (Table B14b). Details on the charting procedures required are specified in USATHAMA QA Program (1990).

\section{Certification of Materials other than SARMs}

The 2ADNT and 4ADNT were obtained from Dr. David Kaplan, U.S. Army Natick Laboratories (Natick, Massachusetts). The 4NT was obtained from either Baker or Eastman-Kodak. These materials were not SARMS but their purity was verified by GC/MS. The 2ADNT and 4NT mass spectra were verified against the Hewlett Packard mass spectrum library entry number \#16458: Benzenamine, 2-methyl-3,5-dinitro- and \#5402: Benzene, 1 methyl,-4-nitro. The top 10 fragments are presented in Table B15. Although a standard mass spectrum for 4ADNT was unavailable, the mass spectrum obtained was consistent with the -structure of the compound. The top 10 fragments are presented in Table B15.

\section{IIX. References}

1. Hubaux, A. and G. Vos (1970) Decisions and detection limits for linear calibration curves. Analytical Chemistry, 42: 849-855. 
2. Jenkins, T.F. (1989) Development of an analytical method for the determination of extractable nitroaromatics and nitramines in soil. Ph.D. dissertation, University of New Hampshire.

3. Jenkins, T.F., P.H. Miyares and M.E. Walsh (1988) An improved RP-HPLC method for determining nitroaromatics and nitramines in water. USA Cold Regions Research and Engineering Laboratory, Special Report 88-23.

4. McLellan, W., W.R. Hartley and M. Brower (1988) Health Advisory for Octahyhro-1,3,5,7tetranitro-1,3,5,7-tetrazocine. Office of Drinking Water, U.S. Environmental Protection Agency, Washington, D.C.

5. USATHAMA (1990) USA Toxic and Hazardous Materials Agency Installation Restoration Program, Quality Assurance Program. Aberdeen Proving Ground, Maryland.
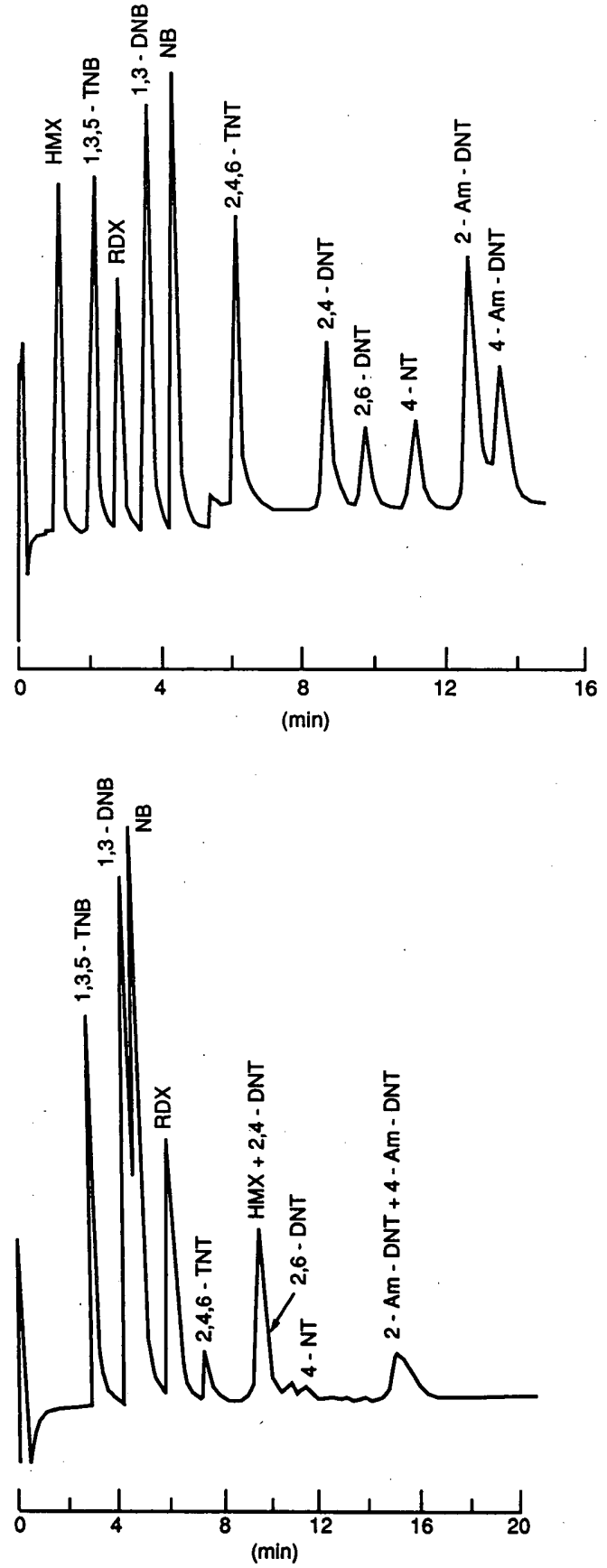

Figure B1. Primary separation for the improved salting-out procedure.

Column: $L C-8(7.5 \mathrm{~cm} \times 4.6 \mathrm{~mm}$, $3 \mu \mathrm{m})$

Eluent: $70.7: 27.8: 1.5(v / v / v)$ $\mathrm{H}_{2} \mathrm{O}-\mathrm{MeOH}-\mathrm{THF}$

Flow: $2.0 \mathrm{~mL} / \mathrm{min}$

Detector, $U V: \quad \lambda=254 \mathrm{~nm}$ Injection volume: $1100 \mu \mathrm{L}$

Figure B2. Confirmation separation for the improved salting-out procedure.

Column: LC-8/LC-CN series (both $3.3 \mathrm{~cm} \times 4.6 \mathrm{~mm}, 3 \mu \mathrm{m})$

Eluent: $70.7: 27.8: 1.5(v / v / v)$ $\mathrm{H}_{2} \mathrm{O}-\mathrm{MeOH}-\mathrm{THF}$

Flow: $1.5 \mathrm{~mL} / \mathrm{min}$

Detector, $U V: \quad \lambda=254 \mathrm{~nm}$

Injection volume: $1100 \mu \mathrm{L}$ 
Table B1. Linear ranges for calibration of analyte standards.

\begin{tabular}{lll} 
& \multicolumn{2}{c}{$\begin{array}{c}\text { Concentration of } \\
\text { standards }(\mu g / L)\end{array}$} \\
Analyte & Low & High \\
\hline HMX & 1.00 & 200 \\
RDX & 1.00 & 200 \\
135TNB & 1.00 & 200 \\
13DNB & 1.00 & 200 \\
NB & 1.06 & 211 \\
246TNT & 1.00 & 200 \\
24DNT & 1.00 & 201 \\
26DNT & 1.01 & 201 \\
4NT & 1.00 & 199 \\
2ADNT & 1.00 & 200 \\
4ADNT & 1.16 & 232 \\
\hline
\end{tabular}

Table B2. Tested concentration ranges for each analyte (prior to preconcentration).

\begin{tabular}{lll} 
& \multicolumn{2}{c}{$\begin{array}{c}\text { Concentration of } \\
\text { samples }\end{array}$} \\
Ang/L) \\
Analyte & Low & High \\
\hline HMX & 0.050 & 1.00 \\
RDX & 0.050 & 1.00 \\
135TNB & 0.025 & 0.500 \\
13DNB & 0.025 & 0.500 \\
NB & 0.053 & 1.06 \\
246TNT & 0.005 & 0.100 \\
24DNT & 0.0025 & 0.050 \\
26DNT & 0.0025 & 0.050 \\
4NT & 0.005 & 0.100 \\
2ADNT & 0.007 & 0.140 \\
4ADNT & 0.006 & 0.116 \\
\hline
\end{tabular}

Table B3. Sensitivity of UV detector for analytes at $254 \mathrm{~nm}$.

\begin{tabular}{lcc} 
Analytes & $\begin{array}{c}\text { Sensitivity* } \\
(\text { Abs per } \mu g / L)\end{array}$ & $\begin{array}{c}\text { Absorbance } \\
\text { at } C R L\end{array}$ \\
\hline HMX & $1.17 \times 10^{-4}$ & $4.82 \times 10^{-3}$ \\
RDX & $9.00 \times 10^{-5}$ & $3.55 \times 10^{-3}$ \\
135TNB & $3.18 \times 10^{-4}$ & $6.24 \times 10^{-3}$ \\
13DNB & $3.17 \times 10^{-4}$ & $4.35 \times 10^{-3}$ \\
NB & $1.79 \times 10^{-4}$ & $1.01 \times 10^{-2}$ \\
246TNT & $1.62 \times 10^{-4}$ & $2.81 \times 10^{-4}$ \\
24DNT & $1.52 \times 10^{-4}$ & $1.73 \times 10^{-4}$ \\
26DNT & $7.52 \times 10^{-5}$ & $7.22 \times 10^{-5}$ \\
4NT & $4.44 \times 10^{-5}$ & $3.02 \times 10^{-4}$ \\
2ADNT & $8.99 \times 10^{-5}$ & $7.69 \times 10^{-4}$ \\
4ADNT & $6.30 \times 10^{-5}$ & $5.20 \times 10^{-4}$ \\
\hline
\end{tabular}

* Sensitivity based on an $1100-\mu \mathrm{L}$ injection of a $100-\mu \mathrm{g} / \mathrm{L}$ standard. † Sensitivity based on concentration factor of 152.
Table B4. Retention times and capacity factors.

COLUMN: $\quad$ LC-8, $7.5 \mathrm{~cm} \times 4.6 \mathrm{~mm}(3 \mu \mathrm{m})$

LC-8/LC-CN (series), $3.3 \mathrm{~cm} \times 4.6 \mathrm{~mm}(3 \mu \mathrm{m})$ (both)

ELUENT: WATER-METHANOL-THF 70.7:27.8:1.5 (v/v/v)

FLOW RATE: $\quad 2.0 \mathrm{~mL} / \mathrm{min}$ (LC-8), $1.5 \mathrm{~mL} / \mathrm{min}$ (LC-8/LC-CN)

WAVELENGTH: $254 \mathrm{~nm} \quad(210 \mathrm{~nm}$ for PETN and NG)

LOOP SIZE: $\quad 1100 \mu \mathrm{L}$

$$
\text { ( } 280 \mathrm{~nm} \text { for TETRAZINE) }
$$

\begin{tabular}{|c|c|c|c|c|}
\hline \multirow[b]{2}{*}{ Analyte } & \multicolumn{2}{|c|}{ Retention time (min) } & \multicolumn{2}{|c|}{ Capacity factor* $\left(\mathrm{K}^{\prime}\right)$} \\
\hline & $\overline{L C-8}$ & $L C-8 / L C \cdot C N$ & $\overline{L C-8}$ & $L C-8 / L C-C N$ \\
\hline $\mathrm{NO}_{3}$ & 0.55 & 0.615 & - & - \\
\hline Tetrazene & unretained & - & - & - \\
\hline Picric acid & unretained & - & - & - \\
\hline 24DNPhenol & 1.18 & - & 1.15 & - \\
\hline SEX & 1.44 & - & 1.62 & - \\
\hline TAX & 1.75 & - & 2.18 & - \\
\hline HMX & 2.19 & 6.91 & 2.98 & 10.24 \\
\hline 26DiAmNT & 2.21 & - & 3.02 & - \\
\hline $135 \mathrm{TNB}$ & 3.09 & 3.35 & 4.62 & 4.45 \\
\hline 3AmNB & 3.17 & - & 4.76 & - \\
\hline TNBA & 3.21 & - & 4.84 & - \\
\hline 14DNB & 3.52 & - & 5.40 & - \\
\hline RDX & 3.60 & 4.97 & 5.55 & 7.09 \\
\hline 24DiAmNT & 3.77 & - & 5.85 & - \\
\hline 13DNB & 4.32 & 4.12 & 6.85 & 5.69 \\
\hline NB & 4.85 & 4.34 & 7.82 & 6.06 \\
\hline 2Am4NT & 5.30 & - & 8.64 & - \\
\hline 12DNB & 5.59 & - & 9.16 & - \\
\hline Benzene & 5.83 & 4.55 & 9.60 & 6.40 \\
\hline 4Am2NT & 6.06 & - & 10.02 & - \\
\hline 246TNT & 6.47 & 5.83 & 10.76 & 8.48 \\
\hline DNA & 7.07 & - & 11.85 & - \\
\hline 24DNT & 8.66 & 7.11 & 14.75 & 10.56 \\
\hline NG & 8.98 & - & 15.33 & - \\
\hline 245TNT & 9.10 & - & 15.55 & - \\
\hline Tetryl & 9.57 & - & 16.40 & - \\
\hline 26DNT & 9.65 & 7.63 & 16.55 & 11.41 \\
\hline $2 \mathrm{NT}$ & 10.65 & 8.08 & 18.36 & 12.14 \\
\hline 4NT & 10.80 & 8.18 & 18.64 & 12.30 \\
\hline 3NT & 11.18 & 8.78 & 19.33 & 13.27 \\
\hline 2ADNT & 12.20 & 9.75 & 21.18 & 14.86 \\
\hline 4ADNT & 12.90 & 10.47 & 22.45 & 16.02 \\
\hline Toluene & 13.90 & 9.37 & 24.27 & 14.24 \\
\hline PETN & 22.44 & - & 39.80 & - \\
\hline 234TNT & 30.00 & - & 53.55 & - \\
\hline
\end{tabular}

* Capacity factor is calculated on the unretained peak of $\mathrm{NO}_{\overline{3}}$.

$K^{\prime}=\left(\frac{\bar{t}_{\mathrm{r}}-\bar{t}_{\mathrm{NO}_{3}}}{\bar{t}_{\mathrm{NO}_{3}}}\right)$

$\bar{t}_{\mathrm{r}}=$ mean retention time of the analyte $(\mathrm{min})$.

$\bar{t}_{\mathrm{NO}_{3}}=$ mean retention time of unretained $\mathrm{NO}_{3}^{-}(\mathrm{min})$.

Table B5. Concentration of stock standards for initial calibration.

\begin{tabular}{lc} 
Analyte & $\begin{array}{c}\text { Concentration } \\
(\mathrm{mg} / \mathrm{L})\end{array}$ \\
\hline HMX & 1000 \\
RDX & 1000 \\
134TNB & 1000 \\
13DNB & 1000 \\
NB & 1060 \\
246TNT & 1000 \\
24DNT & 1000 \\
26DNT & 1010 \\
4NT & 997 \\
2ADNT & 702 \\
4ADNT & 579 \\
\hline
\end{tabular}


Table B6. Concentration of the analytes in the combined and precertification calibration standards $(\mu \mathrm{g} / \mathrm{L})$.

\begin{tabular}{lcccrcrrrrrr} 
Label & $H M X$ & $135 T N B$ & $R D X$ & $13 D N B$ & $N B$ & $246 T N T$ & $24 D N T$ & $26 D N T$ & $4 N T$ & $2 A D N T$ & $4 A D N T$ \\
\hline X,XX & 10,010 & 10,010 & 10,000 & 10,010 & 10,600 & 10,000 & 10,050 & 10,050 & 9,970 & 10,000 & 11,600 \\
A,AA & 200 & 200 & 200 & 200 & 211 & 200 & 201 & 201 & 199 & 200 & 232 \\
B,BB & 100 & 100 & 100 & 100 & 106 & 100 & 100 & 100 & 100 & 100 & 116 \\
C,CC & 40.0 & 40.0 & 40.0 & 40.0 & 42.3 & 40.0 & 40.1 & 40.2 & 39.9 & 40.0 & 46.3 \\
D,DD & 20.0 & 20.0 & 20.0 & 20.0 & 21.1 & 20.0 & 20.1 & 20.1 & 19.9 & 20.0 & 23.2 \\
E,EE & 10.0 & 10.0 & 10.0 & 10.0 & 10.6 & 10.0 & 10.0 & 10.0 & 10.0 & 10.0 & 11.6 \\
F,FF & 4.00 & 4.00 & 4.00 & 4.00 & 4.23 & 4.00 & 4.01 & 4.02 & 3.99 & 4.00 & 4.63 \\
G,GG & 2.00 & 2.00 & 2.00 & 2.00 & 2.11 & 2.00 & 2.01 & 2.01 & 1.99 & 2.00 & 2.32 \\
H,HH & 1.00 & 1.00 & 1.00 & 1.00 & 1.06 & 1.00 & 1.00 & 1.00 & 1.00 & 1.00 & 1.16 \\
\hline
\end{tabular}

Table B7. Dilutions for precertification calibration standards. All dilutions are in water.

\begin{tabular}{|c|c|c|c|c|c|}
\hline \multicolumn{4}{|c|}{ Dilution pattern } & \multirow[b]{2}{*}{$\begin{array}{l}\text { Flask } \\
(m L)\end{array}$} & $\begin{array}{l}\text { Approximate } \\
\text { concentration }\end{array}$ \\
\hline Stando & $\begin{array}{l}\text { ries } I \\
\text { liquot of }(m L)\end{array}$ & Standa & $\begin{array}{l}\text { ies } 2 \\
\text { liquot of }(m L)\end{array}$ & & $\begin{array}{l}\text { of analytes* } \\
(\mu \mathrm{g} / / L)\end{array}$ \\
\hline A & 2.00 of $X^{\dagger}$ & $\mathrm{AA}$ & 2 of $\mathrm{XX} \dagger$ & 100 & 200 \\
\hline B & 1.00 of $X$ & BB & 2 of $X X$ & 100 & 100 \\
\hline C & 20.0 of $A$ & $\mathrm{CC}$ & 20 of $\mathrm{AA}$ & 100 & 40.0 \\
\hline D & 10.0 of $\mathrm{A}$ & $\mathrm{DD}$ & 10 of $A A$ & 100 & 20.0 \\
\hline E & 10.0 of $B$ & $\mathrm{EE}$ & 10 of $B B$ & 100 & 10.0 \\
\hline $\mathbf{F}$ & 10.0 of $\mathrm{C}$ & FF & 10 of $C C$ & 100 & 4.00 \\
\hline G & 2.00 of $B$ & GG & 2 of $B B$ & 100 & 2.00 \\
\hline $\mathrm{H}$ & 1.00 of $B$ & HH & 1 of $B B$ & 100 & 1.00 \\
\hline
\end{tabular}

* See Table B6 for exact concentrations for each analyte.

† Solutions $\mathrm{X}$ and $\mathrm{XX}$ are the respective combined analyte stock standard solutions.
Table B8. Certified Reporting Limits (CRL) for the improved salting-out extraction method.

\begin{tabular}{lc} 
Analytes & $\begin{array}{c}C R L \\
(\mu g / L)\end{array}$ \\
\hline HMX & 0.271 \\
RDX & 0.260 \\
135TNB & 0.129 \\
13DNB & 0.090 \\
NB & 0.372 \\
246TNT & 0.011 \\
24DNT & 0.007 \\
26DNT & 0.006 \\
4NT & 0.045 \\
2ADNT & 0.056 \\
4ADNT & 0.054 \\
\hline
\end{tabular}

Table B9. Concentration of the analytes in the combined and initial calibration standards $(\mu \mathrm{g} / \mathrm{L})$.

\begin{tabular}{lcccccccccccc} 
Label & $H M X$ & $135 T N B$ & $R D X$ & $13 D N B$ & $N B$ & $246 T N T$ & $24 D N T$ & $26 D N T$ & $4 N T$ & $2 A D N T$ & $4 A D N T$ \\
\hline N & 10,010 & 10,010 & 10,000 & 10,010 & 10,600 & 10,000 & 10,030 & 10,050 & 9,970 & 10,000 & 11,586 \\
P & 200 & 200 & 200 & 200 & 211 & 200 & 201 & 201 & 199 & 200 & 232 \\
Q & 100 & 100 & 100 & 100 & 106 & 100 & 100 & 100 & 100 & 100 & 116 \\
R & 40.0 & 40.0 & 40.0 & 40.0 & 42.3 & 40.0 & 40.1 & 40.2 & 39.9 & 40.0 & 46.3 \\
S & 20.0 & 20.0 & 20.0 & 20.0 & 21.1 & 20.0 & 20.1 & 20.1 & 19.9 & 20.0 & 23.2 \\
T & 10.0 & 10.0 & 10.0 & 10.0 & 10.6 & 10.0 & 10.0 & 10.0 & 10.0 & 10.0 & 11.6 \\
U & 4.00 & 4.00 & 4.00 & 4.00 & 4.23 & 4.00 & 4.01 & 4.02 & 3.99 & 4.00 & 4.63 \\
V & 2.00 & 2.00 & 2.00 & 2.00 & 2.11 & 2.00 & 2.01 & 2.01 & 1.99 & 2.00 & 2.32 \\
W & 1.00 & 1.00 & 1.00 & 1.00 & 1.06 & 1.00 & 1.00 & 1.00 & 1.00 & 1.00 & 1.16 \\
\hline
\end{tabular}


Table B10. Dilutions for initial calibration standards. All dilutions are in water.

\begin{tabular}{lccc} 
Standard & $\begin{array}{c}\text { Aliquot of } \\
(\mathrm{mL})\end{array}$ & $\begin{array}{c}\text { Size of flask } \\
(\mathrm{mL})\end{array}$ & $\begin{array}{c}\text { Concentrations* } \\
(\mu \mathrm{g} / \mathrm{L})\end{array}$ \\
\hline $\mathrm{P}$ & 2.00 of $\mathrm{N}^{\dagger}$ & 100 & 200 \\
$\mathrm{Q}$ & 1.00 of $\mathrm{N}$ & 100 & 100 \\
$\mathrm{R}$ & 20.00 of $\mathrm{P}$ & 100 & 40.0 \\
$\mathrm{~S}$ & 10.00 of $\mathrm{P}$ & 100 & 20.0 \\
$\mathrm{~T}$ & 10.00 of $\mathrm{Q}$ & 100 & 10.0 \\
$\mathrm{U}$ & 10.00 of $\mathrm{R}$ & 100 & 4.00 \\
$\mathrm{~V}$ & 2.00 of $\mathrm{Q}$ & 100 & 2.00 \\
$\mathrm{~W}$ & 1.00 of $\mathrm{Q}$ & 100 & 1.00 \\
\hline
\end{tabular}

* See Table B9 for exact concentrations for each analyte. † Solution $\mathbf{N}$ is the combined analyte stock standard.
Table B11. Concentration of combined analyte calibration solution (NN) and daily calibration solution (PP).

\begin{tabular}{lccc} 
Analyte & $\begin{array}{c}\text { Stock } \\
(\mathrm{mg} / \mathrm{L})\end{array}$ & $\begin{array}{c}N N \\
(\mu g / L)\end{array}$ & $\begin{array}{c}P P \\
(\mu g / L)\end{array}$ \\
\hline HMX & 1000 & 10010 & 100 \\
RDX & 1000 & 10000 & 100 \\
135TNB & 1000 & 5000 & 50.0 \\
13DNB & 1000 & 5000 & 50.0 \\
NB & 1050 & 10600 & 106 \\
246TNT & 1000 & 1000 & 10.0 \\
24DNT & 1000 & 501 & 5.02 \\
26DNT & 1010 & 502 & 5.02 \\
4NT & 997 & 997 & 9.97 \\
2ADNT & 702 & 1400 & 14.0 \\
4ADNT & 579 & 1160 & 11.6 \\
\hline
\end{tabular}

Table B12. Concentration of certification combined stock and spiking solutions $(\mu \mathrm{g} / \mathrm{L})$.

\begin{tabular}{lrrrrrr} 
Analytes & $Q Q^{*}$ & $R R$ & $S S$ & $T T$ & $U U$ & $V V$ \\
\hline HMX & 10010 & 2002 & 1000 & 400 & 200 & 100 \\
135TNB & 5000 & 1000 & 500 & 200 & 100 & 50 \\
RDX & 10000 & 2000 & 1000 & 400 & 200 & 100 \\
13DNB & 5000 & 1000 & 500 & 200 & 100 & 50 \\
NB & 10600 & 2110 & 1060 & 422 & 211 & 106 \\
246TNT & 1000 & 200 & 100 & 40.0 & 20.0 & 10.0 \\
24DNT & 502 & 100 & 50.2 & 20.1 & 10.0 & 5.02 \\
26DNT & 502 & 101 & 50.2 & 20.1 & 10.1 & 5.02 \\
p-NT & 997 & 199 & 99.7 & 39.9 & 19.9 & 9.97 \\
2ADNT & 1400 & 281 & 140 & 56.2 & 28.1 & 14.0 \\
4ADNT & 1160 & 232 & 116 & 46.4 & 23.2 & 11.6 \\
\hline
\end{tabular}

* Solution $\mathrm{QQ}$ is the certification combined stock solution.

Table B13. Dilution outline of certification spiking solutions.* All dilutions are in acetonitrile.

\begin{tabular}{cccc} 
Solution & Level & $\begin{array}{c}\text { Volume of } Q Q \\
(\mathrm{~mL})\end{array}$ & $\begin{array}{c}\text { Volume of flask } \\
(\mathrm{mL})\end{array}$ \\
\hline RR & $10 \times$ & 20.0 & 100 \\
SS & $5 \times$ & 10.0 & 100 \\
TT & $2 \times$ & 4.00 & 100 \\
UU & $1 \times$ & 2.00 & 100 \\
VV & $0.5 \times$ & 1.00 & 100 \\
\hline
\end{tabular}

*Concentration of analytes in the certification spiking solutions are listed in Table B12. 
Table B14. Initial control limits for percent recoveries.

\begin{tabular}{|c|c|c|c|c|c|c|c|c|}
\hline . & $135 T N B$ & $R D X$ & $13 D N B$ & $246 T N T$ & $24 D N T$ & $26 D N T$ & $2 A D N T$ & $4 A D N T$ \\
\hline \multicolumn{9}{|c|}{ a. From duplicate certification samples (10x) } \\
\hline \multicolumn{9}{|l|}{ For means } \\
\hline UWL & 181 & 105 & 128 & 109 & 115 & 114 & 117 & 117 \\
\hline UCL & 198 & 106 & 147 & 120 & 129 & 128 & 128 & 129 \\
\hline LWL & 113 & 97.3 & 55.4 & 67.6 & 60.6 & 61.1 & 73.3 & 68.1 \\
\hline LCL & 95.5 & 95.5 & 37.0 & 57.1 & 46.8 & 47.7 & 62.3 & 55.9 \\
\hline \multicolumn{9}{|l|}{ For range } \\
\hline UWL & 68.4 & 7.3 & 73.2 & 41.9 & 55.0 & 53.5 & 43.8 & 48.8 \\
\hline UCL & 89.0 & 9.5 & 95.2 & 54.6 & 71.5 & 69.6 & 57.0 & 63.5 \\
\hline LCL & 0.0 & 0.0 & 0.0 & 0.0 & 0.0 & 0.0 & 0.0 & 0.0 \\
\hline \multirow[t]{2}{*}{ LWL } & 0.0 & 0.0 & 0.0 & 0.0 & 0.0 & 0.0 & 0.0 & 0.0 \\
\hline & \multicolumn{8}{|c|}{ b. Of $2 \times$ certification samples using 3-point moving averages } \\
\hline \multicolumn{9}{|c|}{ 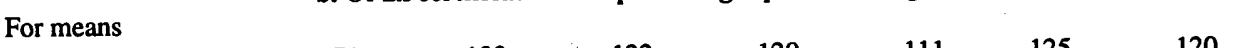 } \\
\hline UWL & 177 & 171 & 133 & 122 & 120 & 111 & 125 & 120 \\
\hline UCL & 179 & 190 & 142 & 132 & 125 & 117 & 139 & 128 \\
\hline LWL & 170 & 94.4 & 94.9 & 85.7 & 98.4 & 88.6 & 67.3 & 87.2 \\
\hline $\mathrm{LCL}$ & 169 & 75.3 & 85.5 & 76.5 & 93.1 & 82.9 & 52.9 & 79.0 \\
\hline \multicolumn{9}{|l|}{ For range } \\
\hline UWL & 9.8 & 115 & 56.7 & 55.2 & 32.1 & 34.0 & 86.7 & 49.3 \\
\hline UCL & 12.2 & 144 & 71.3 & 69.3 & 40.3 & 42.7 & 109 & 61.9 \\
\hline $\mathrm{LCL}$ & 0.0 & 0.0 & 0.0 & 0.0 & 0.0 & 0.0 & 0.0 & 0.0 \\
\hline LWL & 0.0 & 0.0 & 0.0 & 0.0 & 0.0 & 0.0 & 0.0 & 0.0 \\
\hline
\end{tabular}

Table B15. Top most intense peak in mass spectrum of 2ADNT, 4ADNT and 4NT.

\begin{tabular}{rrrrrrr}
\multicolumn{2}{c}{$2 A D N T$} & \multicolumn{2}{c}{4 4ADT } & \multicolumn{2}{c}{$4 N T$} \\
\cline { 5 - 7 } m/e & $\begin{array}{c}\text { Relative } \\
\text { abundance }\end{array}$ & m/e & $\begin{array}{c}\text { Relative } \\
\text { abundance }\end{array}$ & m/e & $\begin{array}{c}\text { Relative } \\
\text { abundance }\end{array}$ \\
\hline & & & & & \\
180 & 100 & 180 & 100 & 137 & 100 \\
197 & 78 & 197 & 60 & 91 & 97 \\
78 & 64 & 104 & 51 & 65 & 85 \\
104 & 41 & 78 & 33 & 39 & 39 \\
77 & 34 & 105 & 30 & 107 & 35 \\
52 & 32 & 52 & 24 & 63 & 25 \\
51 & 26 & 77 & 24 & 77 & 22 \\
105 & 23 & 51 & 22 & 79 & 18 \\
134 & 19 & 93 & 17 & 89 & 17 \\
133 & 17 & 94 & 15 & 51 & 17 \\
\hline
\end{tabular}




\title{
APPENDIX C: METHOD DOCUMENTATION IN USATHAMA (1990) FORMAT
}

\author{
Certification \\ Low-level, Direct Injection Method for \\ Determination of Nitroaromatics and Nitramines in Water
}

\section{Summary}

A. Analytes: The following analytes can be determined using this analytical method: $135 T N B$, RDX, 13DNB, NB, 246TNT, 24DNT, 26DNT, 4NT, 2ADNT and 4ADNT.

B. Matrix: This method is suitable for the analysis of ground or surface water samples.

C. General method: This method involves the addition of $1 \%$ methanol to a water sample, filtration through a $0.5-\mu \mathrm{m}$ Millex SR filter membrane and direct injection of $1100 \mu \mathrm{L}$ of sample onto a reversed-phase HPLC column. Since the solvent strength of the injected sample is low for the reversed-phase column, the analytes in the injected sample are focused on the front of the column during sample introduction. Separation is achieved on an LC-8 $(7.5 \mathrm{~cm} \times 4.6 \mathrm{~mm}, 3 \mu \mathrm{m})$ column under isocratic conditions with a ternary eluent composed of 70.7:27.8:1.5 (v/v/v) water-methanoltetrahydrofuran at $2.0 \mathrm{~mL} / \mathrm{min}$. Determination is obtained on a UV detector at $244 \mathrm{~nm}$. It is essential to use a precolumn in this method to protect the analytical column from large pressure fluctuations during injection.

\section{Application}

A. Tested concentration range: The ranges of analyte concentration over which this method was tested are shown in Table $\mathrm{C} 1$.

B. Sensitivity: The response of the UV detector at $244 \mathrm{~nm}$ for each analyte under the conditions described above are shown in Table $\mathrm{C} 2$.

C. Reporting limits: Certified Reporting Limits (CRL) for the following analytes were determined over a four-day period using the method of Hubaux and Vos (1970), as described in the USATHAMA Quality Assurance Program (1990). CRL values for each analytes are presented in Table C3.

D. Interferences: Retention times for the analytes of interest and several potential interferences are presented in Table $\mathrm{C} 4$. The major potential co-elution problems are Tetryl eluting with 26DNT, and 2NT eluting with 4NT. Determination of HMX using this method can only be achieved at a rather high CRL since HMX elutes on the tail of the water peak.

E. Analysis rate: Because of the large sampling loop size $(1100 \mu \mathrm{L})$, samples must be manually injected. The run time is about 15 minutes/sample. About 20 samples can be analyzed per day along with appropriate calibration standards, blanks and quality control samples.

F. Safety information: The normal safety procedures associated with potentially toxic organic substances should be followed.

\section{Apparatus and Chemicals}

\section{A. Glassware/hardware:}

1. Volumetric pipettes: glass, $10 \mathrm{~mL}$.

2. Scintillation vials: $20 \mathrm{~mL}$, glass (2/sample).

3. Disposable syringes: Plastipak, $20 \mathrm{~mL}$ (1/sample).

4. Filters: $0.5 \mu \mathrm{m}$ Millex SR, disposable (1/sample).

5. Syringes: Glass, $100 \mu \mathrm{L}, 5 \mathrm{~mL}$. 


\section{B. Instrumentation:}

1. HPLC System: Spectra Physics SP8810 pump (or equivalent), an injector equipped with an $1100-\mu \mathrm{L}$ injection loop and a Spectra Physics SP 8490 UV detector set at $244 \mathrm{~nm}$ (or equivalent variable wavelength detector ${ }^{*}$ ). The RP-HPLC column is eluted with an eluent composed of watermethanol-tetrahydrofuran $(70.7: 27.8: 1.5[\mathrm{v} / \mathrm{v} / \mathrm{v}])$ at $2.0 \mathrm{~mL} / \mathrm{min}$.

2. Strip chart recorder (Linear 500 or equivalent).

3. Digital Integrator (HP3393A or equivalent) equipped with an external disk drive (HP9114B or equivalent).

4. LC-8 (Supelco) RP-HPLC column, $7.5 \mathrm{~cm} \times 4.6 \mathrm{~mm}(3 \mu \mathrm{m})$.

5. LC-8 (Supelco) RP-HPLC column, $3.3 \mathrm{~cm} \times 4.6 \mathrm{~mm}(3 \mu \mathrm{m})$.

6. LC-CN (Supelco) RP-HPLC column, $3.3 \mathrm{~cm} \times 4.6 \mathrm{~mm}(3 \mu \mathrm{m})$.

C. Analytes:

1. 135TNB (1,3,5-trinitrobenzene)

BP: decomposes

MP: $122^{\circ} \mathrm{C}$

Solubility in water at $25^{\circ} \mathrm{C}: 385 \mathrm{mg} / \mathrm{L}$

Octanol/water partition coefficient: 15

CAS \#99-35-4.

2. RDX (hexahydro-1,3,5,-trinitro-1,3,5,-triazine)

BP: decomposes

MP: $203.5^{\circ} \mathrm{C}$

Solubility in water at $25^{\circ} \mathrm{C}: 60 \mathrm{mg} / \mathrm{L}$

Octanol/water partition coefficient: 7.5

CAS \#121-82-4.

3. 13DNB (1,3-dinitrobenzene)

BP: $302^{\circ} \mathrm{C}$

MP: $122^{\circ} \mathrm{C}$

Solubility in water at $25^{\circ} \mathrm{C}: 533 \mathrm{mg} / \mathrm{L}$

Octanol/water partition coefficient: 31

CAS \#99-65-0.

4. NB (Nitrobenzene)

BP: $211^{\circ} \mathrm{C}$

MP: $5.7^{\circ} \mathrm{C}$

Solubility in water at $20^{\circ} \mathrm{C}: 1900 \mathrm{mg} / \mathrm{L}$

Octanol/water partition coefficient: 71

CAS \#98-95-3.

5. 246TNT (2,4,6-trinitrotoluene)

BP: $280^{\circ} \mathrm{C}$ (explodes)

MP: $80.1^{\circ} \mathrm{C}$

Solubility in water: $130 \mathrm{mg} / \mathrm{L}$

Octanol/water partition coefficient: 68

CAS \#118-96-7.

6. 24DNT (2,4-dinitrotoluene)

BP: $300^{\circ} \mathrm{C}$ (decomposes)

MP: $70^{\circ} \mathrm{C}$

Solubility in water: $300 \mathrm{mg} / \mathrm{L}$

Octanol/water partition coefficient: 95

* A variable wavelength detector rather than a diode array detector is specified because of superior signal-to-noise ratio characteristics. 
CAS \#121-14-2.

7. 26DNT (2,6-dinitrotoluene)

MP: $66^{\circ} \mathrm{C}$

Solubility in water $\left(25^{\circ} \mathrm{C}\right): 206 \mathrm{mg} / \mathrm{L}$

Octanol/water partition coefficient: 97

CAS \#606-20-2.

8. 4NT (p-nitrotoluene)

MP: $238^{\circ} \mathrm{C}$

BP: $54^{\circ} \mathrm{C}$

Octanol/water partition coefficient: 234

CAS \#99-99-0.

9. 2ADNT (2-amino-4,6-dinitrotoluene)

Octanol/water partition coefficient: $88.2 *$

CAS \#35572-78-2.

10. 4ADNT (2-amino-4,6-dinitrotoluene)

Octanol/water partition coefficient: $81.5^{*}$

CAS \#1946-51-0.

D. Solvents and Chemicals:

1. Methanol-HPLC grade.

2. Tetrahydrofuran (THF)-HPLC grade.

3. Acetonitrile-HPLC grade.

4. Water-reagent grade.

5. 135TNB-SARM quality.

6. RDX-SARM quality.

7. 13DNB-SARM quality.

8. NB-reagent grade.

9. 246TNT-SARM quality.

10. 24DNT—reagent grade.

11. 26DNT-reagent grade.

12. 4NT—reagent grade.

13. 2ADNT-reagent grade.

14. 4ADNT-reagent grade.

\section{Calibration}

A.Preparation of standards: Solid material (SARM or reagent grade) for each analyte was dried to constant weight in a vacuum desiccator in the dark. Approximately $0.1 \mathrm{~g}(100 \mathrm{mg})$ of each dried SARM or dried reagent was weighed out to the nearest $0.1 \mathrm{mg}$, transferred to individual $100-\mathrm{mL}$ volumetric flasks and diluted to volume with HPLC grade acetonitrile. Stock standards are stored in a refrigerator at $4^{\circ} \mathrm{C}$ in the dark. Stock standards are usable for a period up to 1 year after the date of preparation. The analyte concentration in each stock standard is about $1000 \mathrm{mg} / \mathrm{L}$.

A combined analyte stock solution (STD A) is prepared by combining $1.00 \mathrm{~mL}$ each of the 135TNB, RDX, 13DNB, NB, 246TNT, 24DNT, 26DNT, 4NT, 2ADNT and 4ADNT analyte stock standards in a $100-\mathrm{mL}$ volumetric flask and diluting to volume with $\mathrm{ACN}$. The concentration of all analytes in STD A is about $10,000 \mu \mathrm{g} / \mathrm{L}$.

A combined aqueous stock standard is prepared by diluting $1.00 \mathrm{~mL}$ of STD A to $100 \mathrm{~mL}$ with reagent grade water in 100-mL volumetric flask. Analyte concentrations in this solution (STD B) are about $100 \mu \mathrm{g} / \mathrm{L}$ and the acetonitrile concentration is about $1.0 \%$.

\footnotetext{
* Estimated (Jenkins 1989).
} 
A combined analyte working standard (STD C) is prepared by diluting a 10.0-mL aliquot of STD $B$ to $100 \mathrm{~mL}$ in a volumetric flask with reagent grade water. Individual calibration standards are prepared by diluting STD $\mathrm{C}$ with reagent grade water as described in Table C5. Calibration standards are stored in a refrigerator at $4^{\circ} \mathrm{C}$ in the dark. STD A (in ACN) is usable for a period up to 28 days. Solution B and diluted calibration standards should be prepared fresh daily.

B. Initial calibration: Aliquots of each aqueous standard are analyzed in duplicate in random order. Acceptability of a linear model for each analyte is assessed using the protocol specified in the USATHAMA QA Manual (1990). Experience indicates that a zero intercept linear model is appropriate. Therefore, the response factor for each analyte is taken to be the slope of the best fit regression line.

C. Daily calibration: Standard STD D (Table C5) is used for daily calibration. This standard is injected in triplicate at the beginning of the run, once at the midpoint of the run and once at the end of the run. Response factors for each analyte are obtained from the mean peak height, and compared with the response factors obtained for the initial calibration. The mean response factor for the daily calibration must agree within $\pm 25 \%$ of the response factor of the initial calibration for the first seven daily calibrations and within two standard deviations of the initial calibration for subsequent calibrations. If the criteria are not met, a new initial calibration must be obtained.

\section{Certification Testing, Preparation of Certification Samples}

Individual analyte certification stock solutions are prepared in the identical manner to that described for the calibration stock standards above. A combined analyte certification solution (solution $\mathrm{AA}$ ) is prepared by diluting $1.00 \mathrm{~mL}$ of stock to $100 \mathrm{~mL}$ with $\mathrm{ACN}$ in a $100-\mathrm{mL}$ volumetric flask. A combined aqueous certification stock solution (solution $\mathrm{C}$ ) is prepared by diluting $1.00 \mathrm{~mL}$ of solution AA to $100 \mathrm{~mL}$ with reagent grade water in a $100-\mathrm{mL}$ volumetric flask.

A combined analyte working certification standard (solution $\mathrm{CC}$ ) is prepared by diluting a 10.0$\mathrm{mL}$ aliquot of solution $\mathrm{C}$ to $100 \mathrm{~mL}$ in a volumetric flask with reagent grade water. Individual certification samples are prepared by diluting solution $\mathrm{CC}$ with reagent grade water as described in Table C6.

Certification samples are prepared by pipetting $10.0 \mathrm{~mL}$ of each certification sample into individual scintillation vials, adding $100 \mathrm{~mL}$ of methanol to each, shaking briefly and filtering each with a Millex SR filter into clean scintillation vials.

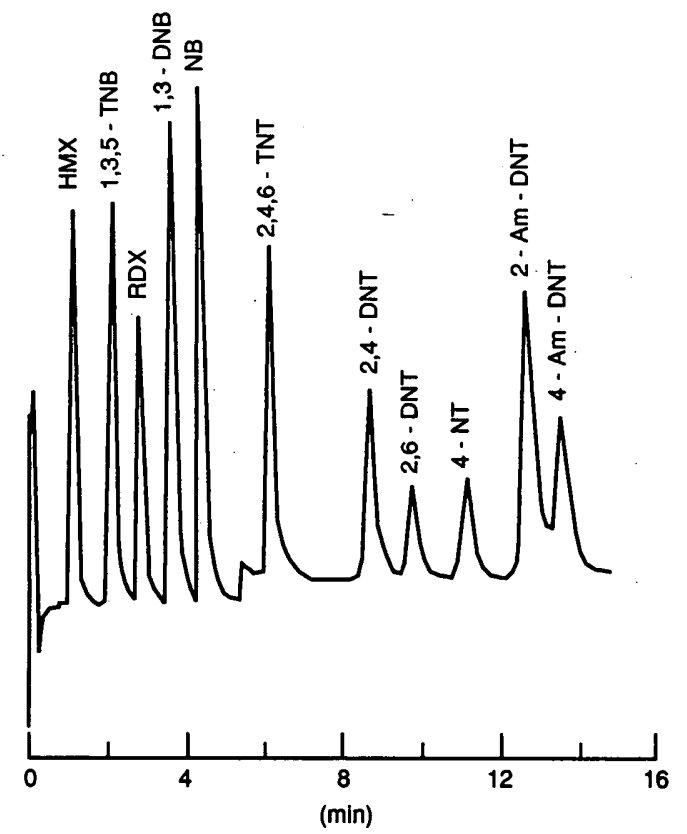

Figure C1. Primary separation.

Column: $\quad L C-8(7.5 \mathrm{~cm} \times 4.6 \mathrm{~mm}, 3 \mu \mathrm{m})$

Eluent: $70.7: 27.8: 1.5(\mathrm{v} / \mathrm{v} / \mathrm{v})$

$\mathrm{H}_{2} \mathrm{O}-\mathrm{MeOH}-\mathrm{THF}$

Flow: $2.0 \mathrm{~mL} / \mathrm{min}$

Detector, $U V: \quad \lambda=254 \mathrm{~nm}$

Injection volume: $1100 \mu \mathrm{L}$ 


\section{Sample Handling and Storage}

A. Sampling procedure: In collecting the sample, the sample container is rinsed three times with sample water, filled to the very top of the container, and capped.

B. Containers: The sample container is an amber glass bottle equipped with a Teflon-lined screw cap.

C. Storage conditions: Samples in the field are stored in coolers in the dark that are kept cool with ice or cold packs. Samples in the laboratory are stored in a refrigerator at $4^{\circ} \mathrm{C}$ in the dark.

D. Storage limits: Samples must be analyzed within 7 days of collection.

\section{Procedure}

A. Sample preparation: A $10.0-\mathrm{mL}$ aliquot of each sample is pipetted into individual $20-\mathrm{mL}$ glass scintillation vials. A $100-\mu \mathrm{L}$ aliquot of methanol is added to each and the vials are shaken briefly. Each sample is then filtered through a $0.5-\mu \mathrm{m}$ Millex SR filter. The first $3 \mathrm{~mL}$ is discarded and the remainder placed in a clean scintillation vial.

B. Determination: Determination of the analyte concentration in each sample is obtained by RPHPLC- UV at $244 \mathrm{~nm}$. A $3.5-\mathrm{mL}$ aliquot of sample is used to overfill an $1100-\mu \mathrm{L}$ sample loop, which is then injected onto an LC-8 column $(7.5 \mathrm{~cm} \times 4.6 \mathrm{~mm}, 3 \mu \mathrm{m})$ and eluted with $2.0 \mathrm{~mL} / \mathrm{min}$ of 70.7:27.8:1.5 (v/v/v) water-methanol-THF. Retention times for analytes and some potential interferences are given in Table C4. An example chromatogram is shown in Figure C1.

C. Confirmation: When peaks are identified as possible analytes of interest on the primary analytical column, the sample is reanalyzed on a second column for analyte confirmation. A $3.5-\mathrm{mL}$ aliquot of sample is used to overfill an $1100-\mu \mathrm{L}$ sample loop, which is then injected onto the following two columns connected in sequence: LC- $8(3.3 \mathrm{~cm} \times 4.6 \mathrm{~mm}, 3 \mu \mathrm{m})$ and LC-CN $(3.3 \mathrm{~cm} \times 4.6 \mathrm{~mm}$, $3 \mu \mathrm{m})$. The columns are eluted with $1.5 \mathrm{~mL} / \mathrm{min}$ of the same eluent used for primary analysis. Retention times are given in Table $\mathrm{C} 4$ and a chromatogram is presented in Figure $\mathrm{C} 2$.

\section{Calculation}

A. Response factors: Since a linear calibration curve with zero intercept is to be expected,

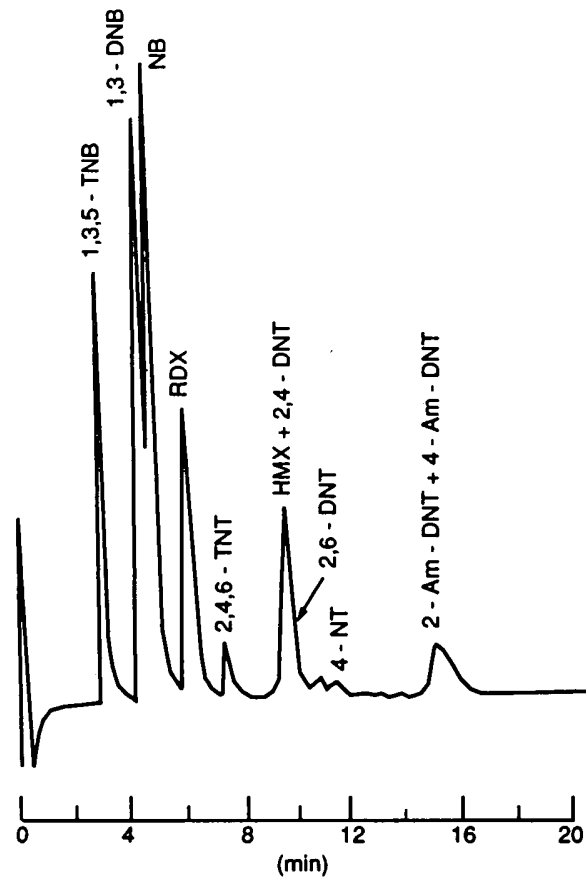

Figure C2. Confirmation separation.

Column: $\quad L C-8 / L C-C N$ series (both $3.3 \mathrm{~cm}$ $\times 4.6 \mathrm{~mm}, 3 \mu \mathrm{m})$

Eluent: $\quad 70.7: 27.8: 1.5(v / v / v)$

$\mathrm{H}_{2} \mathrm{O}-\mathrm{MeOH}-\mathrm{THF}$

Flow: $1.5 \mathrm{~mL} / \mathrm{min}$

Detector, $U V: \quad \lambda=254 \mathrm{~nm}$

Injection volume: $1100 \mu \mathrm{L}$ 
calculations of daily results are obtained using response factors calculated for each analyte. The mean response $(R)$ for each analyte from repeated determinations of STDD is obtained in either peak area or peak height units. The response factor $(R F)$ for each analyte is obtained by dividing the mean response by the known concentration $(C)$ in units of $\mu \mathrm{g} / \mathrm{L}$.

$$
R F=\frac{\bar{R}}{C} .
$$

B. Analyte concentration: The concentrations $(\mu \mathrm{g} / \mathrm{L})$ of each analyte $\left(C_{\mathrm{a}}\right)$ are obtained by dividing the response for each analyte $\left(R_{\mathrm{a}}\right)$ by the appropriate response factor $\left(R F_{\mathrm{a}}\right)$.

$$
C_{\mathrm{a}}=\frac{R_{\mathrm{a}}}{R F_{\mathrm{a}}}
$$

\section{Daily Quality Control}

A. Control spikes: Spiked water samples are prepared as described for the Class 1 method in the USATHAMA QA Program (1990). This requires the use of a method blank, a single spike at two times the certified reporting limit and duplicate spikes at ten times the certified reporting limit for each analytical lot. Control spikes are prepared using the appropriate spiking solution in an identical manner as described in Section V.

B. Control charts: The control charts required are described for Class 1 methods in USATHAMA QA Program (1990). This will require use of standard Shewhart X and R charts for the duplicate high spike and moving average $X$ and $R$ charts for the single low spike. Details on the charting procedures required are specified in USATHAMA QA Program (1990).

\section{References}

1. USATHAMA (1990) U.S. Army Toxic and Hazardous Materials Agency Quality Assurance Program, January 1990. Aberdeen Proving Ground, Maryland.

2. Hubaux, A. and G. Vos (1970) Decision and detection limits for linear calibration curves. Analytical Chemistry, 42: 849-855.

3. Jenkins, T.F. (1989) Development of an analytical method for the determination of extractable nitroaromatics and nitramines in soil. Ph.D. dissertation, University of New Hampshire. 
Table C1. Tested concentration ranges for each analyte.

\begin{tabular}{lc} 
Analyte & $\begin{array}{c}\text { Concentration } \\
\text { range tested } \\
(\mu g / L)\end{array}$ \\
\hline 135TNB & 0.10 to 2.00 \\
RDX & 0.10 to 2.00 \\
13DNB & 0.10 to 2.00 \\
NB & 0.10 to 2.00 \\
246TNT & 0.10 to 2.00 \\
24DNT & 0.10 to 2.00 \\
26DNT & 0.10 to 2.00 \\
4NT & 0.10 to 2.00 \\
2ADNT & 0.10 to 2.00 \\
4ADNT & 0.10 to 2.00 \\
\hline
\end{tabular}

Table C2. Sensitivity of UV detector for analytes at $244 \mathrm{~nm}$ using LC-8 separation described.

\begin{tabular}{lc} 
Analyte & $\begin{array}{c}\text { Concentration } \\
\text { (absorbance units per } \mu g / L \text { ) }\end{array}$ \\
\hline 135TNB & $5.59 \times 10^{-4}$ \\
RDX & $1.45 \times 10^{-4}$ \\
13DNB & $4.00 \times 10^{-4}$ \\
NB & $1.19 \times 10^{-4}$ \\
246TNT & $2.18 \times 10^{-4}$ \\
24DNT & $1.59 \times 10^{-4}$ \\
26DNT & $1.01 \times 10^{-4}$ \\
4NT & $2.68 \times 10^{-5}$ \\
2ADNT & $1.18 \times 10^{-4}$ \\
4ADNT & $1.05 \times 10^{-4}$ \\
\hline
\end{tabular}

Table C3. Certified reporting limits (CRL).

\begin{tabular}{lc} 
Analyte & $\begin{array}{c}C R L \\
(\mu g / L)\end{array}$ \\
\hline 135TNB & 1.07 \\
RDX & 0.62 \\
13DNB & 0.18 \\
NB & 0.66 \\
246TNT & 0.17 \\
24DNT & 0.26 \\
26DNT & 0.47 \\
4NT & 1.06 \\
2ADNT & 0.63 \\
4ADNT & 0.99 \\
\hline
\end{tabular}

Table C4. Retention times for major analytes and potential interferences for primary analysis and second column confirmation.

\begin{tabular}{lcc} 
& \multicolumn{2}{c}{ Retention time $(\mathrm{min})$} \\
\cline { 2 - 3 } Compound & $L C-8$ & $L C-8 / L C-C N$ \\
\hline HMX & 2.2 & 6.9 \\
135TNB & 3.0 & 3.4 \\
RDX & 3.5 & 5.0 \\
13DNB & 4.2 & 4.1 \\
NB & 4.9 & 4.3 \\
Benzene & 5.8 & 4.6 \\
246DNT & 6.3 & 5.8 \\
24DNT & 8.3 & 7.1 \\
Tetryl & 9.2 & 9.8 \\
26DNT & 9.3 & 7.6 \\
2NT & 10.4 & 8.1 \\
4NT & 10.5 & 8.2 \\
3NT & 11.2 & 8.8 \\
2ADNT & 11.7 & 9.8 \\
4ADNT & 12.4 & 10.5 \\
Toluene & 13.2 & 9.4 \\
\hline
\end{tabular}

Table C5. Dilution procedure for individual calibration standards.

\begin{tabular}{lcc}
$\begin{array}{c}\text { Calibration } \\
\text { standard }\end{array}$ & $\begin{array}{c}\text { Volume of STD C } \\
\text { to } 100 \mathrm{~mL}\end{array}$ & $\begin{array}{c}\text { Analyte concentration } \\
(\mu \mathrm{g} / \mathrm{L})\end{array}$ \\
\hline D & 20 & 2 \\
E & 10 & 1 \\
F & 4 & 0.4 \\
G & 2 & 0.2 \\
H & 1 & 0.1 \\
\hline
\end{tabular}

Table C6. Dilution procedure for preparation of certification samples.

\begin{tabular}{ccc}
$\begin{array}{c}\text { Certification } \\
\text { sample }\end{array}$ & $\begin{array}{c}\text { Volume of } \\
\text { solution } C C(\mathrm{~mL}) \\
\text { diluted to } 100 \mathrm{~mL}\end{array}$ & $\begin{array}{c}\text { Analyte } \\
\text { concentration } \\
(\mu \mathrm{g} / \mathrm{L})\end{array}$ \\
\hline Blank & 0 & - \\
$0.5 \mathrm{X}$ & 1 & 0.1 \\
1X & 2 & 0.2 \\
2X & 4 & 0.4 \\
5X & 10 & 1 \\
10X & 20 & 2 \\
\hline
\end{tabular}




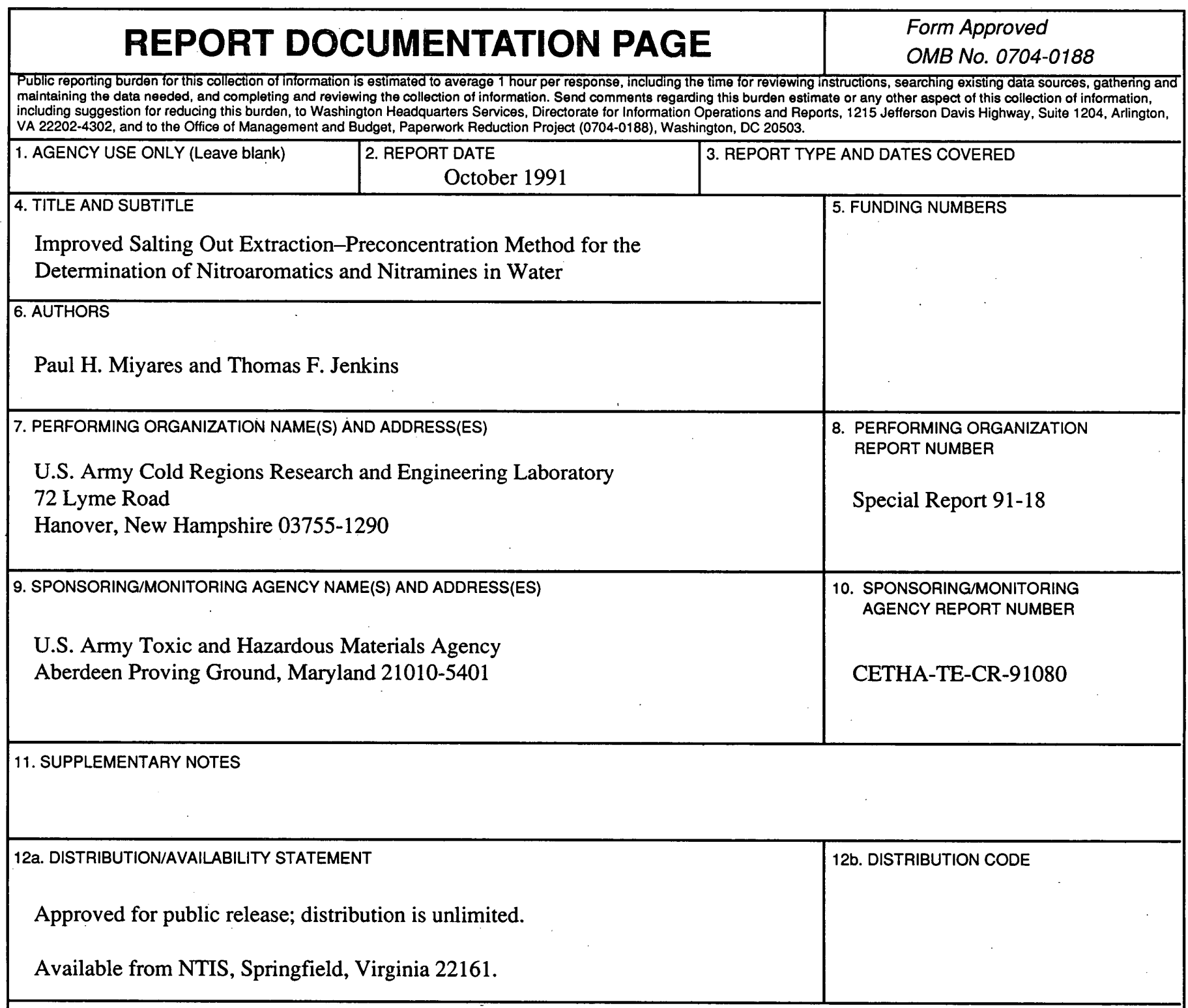

13. ABSTRACT (Maximum 200 words)

An improved salting-out extraction-preconcentration, RP-HPLC-UV protocol for the determination of nitroaromatics and nitramines in water was developed. The method involves saturating a $760-\mathrm{mL}$ water sample with $\mathrm{NaCl}$ and extracting with acetonitrile $(\mathrm{ACN})$. Collected extracts are then preconcentrated and solvent exchanged to water via a Kuderna-Danish evaporator. Analysis involves solute focusing by introducing an $1100-\mathrm{mL}$ sample onto a LC-8 $(7.5-\mathrm{cm}, 3-\mu \mathrm{m})$ column eluted with water, $\mathrm{MeOH}$ and THF (70.7:27.8:1:5 [v/v/v]) at $2.0 \mathrm{~mL} / \mathrm{min}$ followed by UV detection at $254 \mathrm{~nm}$. A direct injection RPHPLC-UV water method was developed concurrently, employing the same separation and detection techniques. Both methods are applicable for simultaneous determination of RDX, TNB, DNB, TNT, 2,4-DNT, 2,6-DNT, 2-Am-DNT and 4-Am-DNT, and HMX (salting-out only) with reporting limits ranging from 0.006 to $0.27 \mu \mathrm{g} / \mathrm{L}$ for the salting-out method and 0.12 to 1.07 $\mu \mathrm{g} / \mathrm{L}$ for the direct injection method. The salting-out extraction procedure is suitable for determination of HMX, RDX, TNT, 2,4-DNT and 2,6-DNT at concentrations below the health advisory and water quality criteria proposed by the USEPA and Oak Ridge National Laboratory.

\begin{tabular}{|c|c|c|c|}
\hline \multirow{2}{*}{$\begin{array}{l}\text { 14. SUBJECT TERMS } \\
\text { Munitions } \\
\text { Munition in water }\end{array}$} & \multirow[b]{2}{*}{$\begin{array}{l}\text { Pollution } \\
\text { Salting-out extraction }\end{array}$} & & $\begin{array}{c}\text { 15. NUMBER OF PAGES } \\
47\end{array}$ \\
\hline & & & 16. PRICE CODE \\
\hline $\begin{array}{l}\text { 17. SECURITY CLASSIFICATION } \\
\text { OF REPORT }\end{array}$ & $\begin{array}{l}\text { 18. SECURITY CLASSIFICATION } \\
\text { OF THIS PAGE }\end{array}$ & $\begin{array}{l}\text { 19. SECURITY CLASSIFICATION } \\
\text { OF ABSTRACT }\end{array}$ & 20. LIMITATION OF ABSTRACT \\
\hline UNCLASSIFIED & UNCLASSIFIED & UNCLASSIFIED & UL \\
\hline
\end{tabular}

